\title{
The Stubenberg meteorite - an LL6 chondrite fragmental breccia recovered soon after precise prediction of the strewn field
}

\author{
Addi BISCHOFF ${ }^{1}$, Jean-Alix BARRAT ${ }^{2}$, Kerstin BAUER ${ }^{3}$, Christoph BURKHARDT ${ }^{1}$, \\ Henner BUSEMANN ${ }^{3}$, Samuel EBERT ${ }^{1}$, Michael GONSIOR ${ }^{4}$, Janina HAKENMÜLLER ${ }^{5}$, \\ Jakub HALODA ${ }^{6}$, Dennis HARRIES ${ }^{7}$, Dieter HEINLEIN ${ }^{8}$, Harald HIESINGER ${ }^{1}$, Rupert \\ HOCHLEITNER $^{9}$, Viktor HOFFMANN ${ }^{10}$, Melanie KALIWODA ${ }^{9}$, Matthias \\ LAUBENSTEIN $^{11}$, Colin MADEN ${ }^{3}$, Matthias M. M. MEIER ${ }^{3}$, Andreas MORLOK ${ }^{1}$, Andreas \\ PACK $^{12}$, Alexander RUF ${ }^{13,14}$, Philippe SCHMITT-KOPPLIN ${ }^{13,14}$, Maria \\ SCHÖNBÄCHLER ${ }^{3}$, Robert C. J. STEELE ${ }^{3}$, Pavel SPURNÝ ${ }^{15}$, and Karl WIMMER ${ }^{16}$
}

${ }^{1}$ Institut für Planetologie, Westfälische Wilhelms-Universität Münster, Wilhelm-Klemm Str. 10, D-48149 Münster, Germany.

${ }^{2}$ Université de Bretagne Occidentale, Institut Universitaire Européen de la Mer, Place Nicolas Copernic, F-29280 Plouzané Cedex, France.

${ }^{3}$ ETH Zurich, Departement Erdwissenschaften, Clausiusstraße 25, CH-8092 Zurich, Switzerland.

${ }^{4}$ University of Maryland, Center for Environmental Science, Chesapeake Biological Laboratory, 146 Williams Street, Solomons, MD-20688, USA.

${ }^{5}$ Max-Planck-Institut für Kernphysik, Saupfercheckweg 1, D-69117 Heidelberg, Germany.

${ }^{6}$ Czech Geological Survey, Geologická 6, CZ-152 00 Praha 5, Czech Republic.

${ }^{7}$ Friedrich-Schiller-Universität Jena, Institut für Geowissenschaften, Carl-Zeiss-Promenade 10, D-07745 Jena, Germany.

${ }^{8}$ German Fireball Network, Lilienstraße 3, D-86156 Augsburg, Germany.

${ }^{9}$ Mineralogische Staatssammlung München (SNSB), Theresienstr. 41, D-80333 München, Germany.

${ }^{10}$ Department of Geosciences, Eberhard Karls University of Tübingen, Hölderlinstr. 12, D-72074Tübingen, Germany

${ }^{11}$ Laboratori Nazionali del Gran Sasso, Istituto Nazionale di Fisica Nucleare, Via G. Acitelli 22, I-67100 Assergi (AQ), Italy.

${ }^{12}$ Universität Göttingen, Geowissenschaftliches Zentrum, Goldschmidtstr. 1, D-37077 Göttingen, Germany.

${ }^{13}$ Helmholtz-Zentrum, München, German Research Center for Environmental Health, Analytical BioGeoChemistry, Ingolstädter Landstraße 1, D-85764 Neuherberg, Germany.

${ }^{14}$ Chair of Analytical Food Chemistry, Technische Universität München, D-85354 Freising-Weihenstephan, Germany

${ }^{15}$ Astronomical Institute of the Czech Academy of Sciences, Fričova 298, CZ-25165 Ondřejov, Czech Republic.

${ }^{16}$ RiesKraterMuseum, Eugene-Shoemaker-Platz 1, D-86720 Nördlingen, Germany.

Corresponding author: Addi Bischoff, Institut für Planetologie, Westfälische WilhelmsUniversität Münster, Wilhelm-Klemm-Str. 10, D-48149 Münster, Germany. Phone: +49-2518333465; E-mail: bischoa@uni-muenster.de

Version: Meteoritics \& Planetary Science; “In Press-Version”, 2017 


\begin{abstract}
On March 6, 2016 at 21:36:51 UT, extended areas of Upper Austria, Bavaria (Germany) and the southwestern part of the Czech Republic were illuminated by a very bright bolide. This bolide was recorded by instruments in the Czech part of the European Fireball Network and it enabled complex and precise description of this event including prediction of the impact area. So far six meteorites totaling $1473 \mathrm{~g}$ have been found in the predicted area. The first pieces were recovered on March 12, 2016 on a field close to the village of Stubenberg (Bavaria).

Stubenberg is a weakly-shocked (S3) fragmental breccia consisting of abundant highly recrystallized rock fragments embedded in a clastic matrix. The texture, the large grain size of plagioclase, and the homogeneous compositions of olivine $\left(\mathrm{Fa}_{31.4}\right)$ and pyroxene $\left(\mathrm{Fs}_{25.4}\right)$ clearly indicate that Stubenberg is an LL6 chondrite breccia. This is consistent with the data on O-, Ti-, and Cr-isotopes. Stubenberg does not contain solar wind implanted noble gases.

Data on the bulk chemistry, IR-spectroscopy, cosmogenic nuclides, and organic components also indicate similarities to other metamorphosed LL chondrites. Noble gas studies reveal that the meteorite has a cosmic ray exposure (CRE) age of $36 \pm 3 \mathrm{Ma}$ and that most of the cosmogenic gases were produced in a meteoroid with a radius of at least $35 \mathrm{~cm}$. This is larger than the size of the meteoroid which entered the Earth's atmosphere, which is constrained to $<20 \mathrm{~cm}$ from short-lived radionuclide data. In combination, this might suggest a complex exposure history for Stubenberg.
\end{abstract}




\section{INTRODUCTION}

On Sunday March 6, 2016 at 21:36:51 UT (corresponding to the late local evening, UT+1h), extended areas of Upper Austria, Bavaria, and the southwestern part of the Czech Republic were illuminated by a very bright fireball. In particular, the inhabitants of Bavaria, where the skies were mostly clear, were stunned by the luminous and sonic effects of the fireball. Observation was difficult in most of Central Europe due to a cloudy sky. Fortunately, parts of western Czech Republic also had partly clear skies in some places and it enabled researchers to obtain the instrumental records provided by the digital autonomous observatories (DAFOs) of the Czech part of the European Fireball Network. These photographic and radiometric records proved to be essential to describe this rare natural event in detail. The cameras at six Czech stations photographed the event at least partly and almost all Czech cameras recorded its light curve by fast photometers with high time resolution of 5000 samples per second. Thanks to these records, the fireball could be described rigorously and with a high reliability and precision (Spurný et al., 2016). Moreover, the impact area of potential meteorites could also be computed and the ground distribution of meteorites could be modeled. This prediction was very precise, because all six recovered meteorites were found almost exactly in the predicted location for the given meteorite masses (Spurný et al., 2016).

In this paper the mineralogical and chemical characteristics of this new meteorite will be presented including data on organics, short-lived cosmogenic radioisotopes, and noble gases. The meteorite "Stubenberg" has been accepted by the Nomenclature Committee (The Meteoritical Bulletin, 2016, in preparation) and preliminary data were published by Ebert and Bischoff (2016) and Spurný et al. (2016). After the meteorite falls of Braunschweig (L6; Bartoschewitz et al., 2017), Žd'ár nad Sázavou (Spurný et al., 2016), and Ejby (H5/6; The Meteoritical Bulletin, 2016, in preparation), Stubenberg is the fourth recovered meteorite fall within less than three years impacting Earth only $\sim 800 \mathrm{~km}$ apart. Less than 10 meteorite falls/year are recovered globally, and hence, this concentration of recorded falls is remarkable.

\section{SAMPLES AND METHODS - SUMMARY}

In order to obtain information about the classification of the rock and to reveal details on chemical, physical, and mineralogical features and characteristics of the rock different analytical methods were applied. This is a brief summary and further details are given in the "Supplementary Materials". Several thin and thick sections and fragments of Stubenberg were 
studied using optical and electron microscopy. Electron microscopic studies with various Scanning and Transmission Electron Microscopes (SEM, TEM) were performed in Münster, Jena, Prague, and Munich and chemical data by electron microprobe were obtained in Münster. Raman spectroscopical investigations (Munich) were conducted with a Horiba Xplora Integrated confocal Laser micro Raman system on an Olympus BX51 microscope.

After homogenizing a 0.5 g-piece, a $200 \mathrm{mg}$ whole-rock sample of fragments and splinters was analyzed for major and trace element concentrations by inductively coupled plasma atomic emission spectroscopy (ICP-AES) and inductively coupled plasma sector field mass spectrometry (ICP-SFMS) following the procedure described by Barrat et al. (2012, 2015, 2016). Cosmogenic radionuclide concentrations were analyzed by means of non-destructive high purity germanium (HPGe) gamma spectroscopy in the underground laboratories at the Laboratori Nazionali del Gran Sasso and at the Max-Planck-Institut für Kernphysik in Heidelberg (Arpesella, 1996, Heusser et al., 2015), and bulk oxygen isotope composition was analyzed by means of laser fluorination in combination with gas source mass spectrometry (Sharp, 1990). The data were normalized to the composition of San Carlos olivine $\left(\delta^{17} \mathrm{O}_{\text {vsmow } 2}=2.715 \%\right.$ o, $\delta^{18} \mathrm{O}_{\text {vSMOW } 2}=5.220 \%$; see Pack et al., 2016) .

For the Ti-Cr isotope analyses sample powders of Stubenberg $(2 \times 50 \mathrm{mg})$ were dissolved and purified using ion exchange chromatographic procedures. Titanium isotope analyses were then carried out using a Thermo Fisher Scientific Neptune Plus multicollector-inductively coupled plasma mass spectrometer (MC-ICPMS) both at the Institut für Planetologie in Münster and at the Institute of Geochemistry and Petrology at ETH Zurich, while Cr isotopes were analyzed in Zurich only. The analytical procedures followed those described in Schönbächler et al. (2004), Williams (2015), and Zhang et al. (2011) for Ti and in Steele and Schönbächler (2016) for $\mathrm{Cr}$ and are described in more detail in the "Supplementary Materials". The noble gases He-Xe present in two bulk samples "I" (23.3 mg) and "II" (71.5 $\mathrm{mg}$ ) were analyzed at ETH Zurich using the standard procedures described in detail by Riebe et al. (2017, in revision).

Regarding physical properties, Fourier transform infrared spectroscopy (FTIR) spectroscopic measurements were undertaken using a Bruker Vertex 70v at the IR/IS laboratory located at the Institut für Planetologie (Münster) and the Magnetic Susceptibility (MS) of various Stubenberg fragments was measured in the strewn field as well as in Nördlingen with the SM30 of ZH Instruments. Additional instrumental details are given in the "Supplementary Materials". A destructive methanolic solvent extraction of organic matter was performed in an 
agate mortar using $50 \mathrm{mg}$ freshly broken fragment of the Stubenberg meteorite. Analytical details and information on the data processing are given in Schmitt-Kopplin et al. (2010, 2012), Tziotis et al. (2011), Hertkorn et al. (2015), and Ruf et al. (2017).

\section{RESULTS}

\section{Fall circumstances and geographic details of find area}

From the detailed light curve of the observed bolide taken by the fast photometers (time resolution 5000 samples/s) as part of the Czech fireball automated cameras (Spurný et al. 2007), it was evident that the initial meteoroid heavily fragmented in the last third of its luminous atmospheric flight. A very complex model of the impact area was produced using precise trajectory data combined with the known wind profile available from balloon data. The distribution pattern of individual meteorites deposited from each particular breakup were directly visible on the light curve, which will be described along with the bolide data elsewhere. The resulting predicted impact area near the village of Stubenberg in Lower Bavaria has a complicated irregular shape (Fig. 1). This prediction was convincingly confirmed by the positions and masses of the recovered meteorites, as described in Fig. 1. The northern part of the strewn field is dominated by forest at an elevation of about $500 \mathrm{~m}$ above sea level, in which the samples M5 and M6 were found (Table 1). Most other areas represent farmland (Fig. 1). Stubenberg is a small village in Lower Bavaria with a population of about 1400 residents.

\section{Petrography and Mineralogy}

\section{Description of hand specimens}

All recovered stones of the Stubenberg meteorite are shown in Fig. 2 and listed in Table 1. The first fragments of one broken individual stone were found six days after the fall. Within several weeks of intensive search six meteorite individuals with a total mass of $1473 \mathrm{~g}$ were recovered. The largest fragment (M5) has a mass of $1320 \mathrm{~g}$ (Figs. 1 and 2e; Table 1), and a bulk density of $3.29 \pm 0.01 \mathrm{~g} / \mathrm{cm}^{3}$. The first recovered piece was heavily-fragmented at the impact location, when hitting the ground. The main mass broke into 3 larger pieces and several smaller fragments (M1a - M1n; Table 1) covering an area of 10 meters in diameter. From the time of impact until recovery the fragmented piece remained in place. The biggest fragment M1b has a weight of $23.58 \mathrm{~g}$ (Fig. 2a); all pieces a 0.1 to $0.3 \mathrm{~mm}$ thick, dark-brown 
to black and fusion crust is mostly well preserved. While the surface of the meteorite is predominantly smooth, the fusion crust shows polygonal cracks in several spots. Meteorite piece M6, weighing 35.89 gram (Fig. 2f), was found as a fragmented individual with two almost perpendicular fracture surfaces not covered by fusion crust. Intensive search did not yield the missing fragments. Close inspection by SEM later showed abundant FeS melt splashes and rare glass droplets on the broken surfaces, suggesting a high altitude break-up event, possibly at the end or slightly after the luminous flight. Cutting the meteorite by wire saw revealed a rather friable rock.

Internally, a greyish, silicate-rich component dominates the meteorite, rare mm-sized fragments are visible, and minor amounts of minerals with metallic lustre are recognizable throughout the rock. Rarely, shock veins are observed consisting of the metallic phases and troilite as confirmed by detailed mineralogical studies on thin sections. Since the rock was found about one week after the fall, it has already been affected by some minor weathering processes as documented in places by the brownish taint on the surfaces of the broken piece.

\section{Mineralogy - texture and compositions of phases}

The brecciated meteorite has abundant fragments with a recrystallized texture and a small number of chondrule relics (Fig. 3). Especially the outlines of former barred-olivine (BO) and radial pyroxene (RP) chondrules are still recognizable (Fig. 3). One of these relic chondrules is a several mm-sized macrochondrule (Weyrauch and Bischoff, 2012). The distribution and obtained abundances of various phases are shown in Figures S1 and listed in Table S1.

Olivine is by far the most abundant phase (53-56 vol\%; Table S1). Generally, the grains are variable in size and show strong undulatory extinction. The olivines are homogeneous in composition throughout all thin sections. The mean composition of 54 analyzed olivines is $\mathrm{Fa}_{31.4 \pm 0.3}$ with a compositional range between 30.5 and $32.2 \mathrm{~mol} \% \mathrm{Fa}$ (Table 2). The low-Ca pyroxenes ( 17 vol\%) and Ca-pyroxenes (6.3 vol\%) have mean compositions of Fs $25.4 \mathrm{Wo}_{2.0}$ and $\mathrm{Fs}_{10.3} \mathrm{Wo}_{43.9}$, respectively (Table 2; Fig. S1). The 43 analyzed low-Ca pyroxenes vary between 24.8 and 26.1 mol\% Fs. Ca-pyroxene has a much lower modal abundance compared with low-Ca pyroxene and is also homogeneous in composition. Raman mapping supports that the dominating phases of Stubenberg are olivine, orthopyroxene, Ca-pyroxene, and Abrich plagioclase. According to the Raman spectra all pyroxenes show very uniform compositions with insignificant variations not only in one single clast, but also from clast to clast. Selected olivine and pyroxene particles have been tested for water $\left(\mathrm{H}_{2} \mathrm{O} / \mathrm{OH}\right)$ contents 
by Raman spectroscopy, but no Raman signals could be detected in the $\mathrm{H}_{2} \mathrm{O}$ Raman spectral region (3400-3700 $\mathrm{cm}^{-1}$ ) due to possible rapid terrestrial weathering of the mineral constituents at the impact location.

Plagioclase (10-13 vol\%; Table S2) is present as quite large crystals often exceeding 100 $\mu \mathrm{m}$ in size (Fig. 3). Mean plagioclase has An- and Or-components of $11.1 \pm 0.4$ and $5.5 \pm 1.2$ mol\%, respectively $(n=42$; Table 2$)$. The compositions vary between 10.3 and $12.1 \mathrm{~mol} \%$ An.Both the phosphates merrillite and $\mathrm{Cl}$-apatite were found in the studied thin sections. $\mathrm{Cl}$ apatite is more abundant than merrillite. Their compositions are listed in Table 2.

Metal and sulfide occur as small grains distributed throughout the entire thin sections. Metallic phases are homogeneously distributed and up to $250 \mu \mathrm{m}$ in apparent size. The chemical compositions of these phases are given in Table S2. In general, kamacite has mean $\mathrm{Ni}-$ and Co-concentrations of 3.9 and $6.1 \mathrm{wt} \%$, respectively. The taenite composition is variable, with $\mathrm{Ni}$ content varying from 41.9 to $48.2 \mathrm{wt} \%$ (average $\sim 44.3 \mathrm{wt} \% \mathrm{Ni}, \sim 1.8 \mathrm{wt} \%$ $\mathrm{Co}, 0.22 \mathrm{wt} \% \mathrm{Cu} ; \mathrm{n}=38$ ). Some grains may be tetrataenite due to slight anisotropy in reflected, polarized light.

Troilite is an abundant phase in Stubenberg (approx. 9 vol\%; Table S1) and is distributed throughout all thin sections, occasionally forming mm-sized aggregates. An approx. $1.5 \mathrm{~mm}$ long, string-shaped aggregate of troilite and Ni-poor pentlandite (molar Fe/Ni 3.3; Table S2) was observed (Fig. 4). Small amounts of pentlandite also occur in association with other troilite grains. Pentlandite was confirmed by TEM using selected area electron diffraction (SAED) obtained on a FIB section (Fig. 4c). At the TEM scale the pentlandite shows strong mosaicism, i.e. poor crystal quality, and sharp boundaries to neighboring troilite. $\{111\}$ and $\{0-11\}$ of pentlandite are nearly parallel with (001) and $\{010\}$ of troilite, respectively (Fig. 4d). This is close to the orientation relationship observed for troilite/pyrrhotite and exsolved pentlandite in terrestrial and meteoritic samples (Harries and Langenhorst, 2013). The coexisting troilite shows good crystal quality and contains abundant subgrain boundaries. Superstructure reflections of pyrrhotite are absent in SAED patterns, indicating nearly stoichiometric FeS.

Chromite occurs as small grains and has mean $\mathrm{MgO}-, \mathrm{Al}_{2} \mathrm{O}_{3}{ }^{-}$, and $\mathrm{TiO}_{2}$-concentrations of 1.5 $\mathrm{wt} \%, 5.2 \mathrm{wt} \%$, and $3.4 \mathrm{wt} \%$, respectively $(\mathrm{n}=14$; Table 2$)$. Chromite has been frequently found in all fragments. It shows anhedral grains up to $100 \mu \mathrm{m}$ and is, according to its Raman spectrum, a high iron low magnesium member of the solid solution. Rarely some grains show deviating peak positions, which point to possibly higher concentrations of $\mathrm{Mg}$ and/or $\mathrm{Al}$. 
Further accessory phases observed are ilmenite with grain sizes up to $50 \mu \mathrm{m}$ (associated with taenite and troilite, or with chromite), metallic copper (grains $<10 \mu \mathrm{m}$, associated with kamacite, taenite), rutile, anatase, and carbon phases (graphite to heavily disordered graphite). The latter three phases were identified by Raman spectroscopy. The two different $\mathrm{TiO}_{2}$ phases anatase and rutile could be clearly identified as single grains by their different Raman spectra (Fig. S2). Rutile displays white to colourless grains up to $20 \mu \mathrm{m}$. Both phases are found in direct contact with ilmenite and chromite. Carbon phases have mainly been detected decorating grain boundaries between silicate and sulfide grains. According to the band width of the main Raman bands they vary between well crystallized graphite and heavily disordered phases. As all measurements have been conducted on simply broken surfaces the disorder cannot be an artifact due to mechanical treatment and contamination by grinding or coating can be excluded. On the broken surface large grains of olivine, pyroxene, feldspar, and troilite are often recognizable as well as $120^{\circ}$ triple junctions between olivine, pyroxene and plagioclase (Fig. 5).

\section{Shock metamorphism and weathering.}

As stated above, based on the study of the thin sections Stubenberg is brecciated (Fig. 3a). The thin sections only show highly-recrystallized fragments having only very rare relic chondrules (type 6). Several shock veins were observed (Fig. 3d). Plagioclase and olivine show undulatory extinction, and the olivines show distinct sets of planar fractures (Fig. 3f). High pressure phases (such as ringwoodite) were searched for by Raman spectroscopy, but could not be detected even in the melt veins. No glass-like or recrystallized plagioclase phases could be found (including feldspar-glasses or maskelynite). The optical features indicate that the rock is weakly shocked (S3; Stöffler et al., 1991; Bischoff and Stöffler, 1992).

The residence time of about 7 days on the ground resulted in first signs of weathering. Locally, areas with a brownish taint are already present resulting from the first breakdown of metals. Though a few rusty spots are clearly recognized with the naked eye on the surface of all samples, alteration phases such as iron oxides-hydroxides or iddingsite (olivine alteration) could not be detected by Raman spectroscopy.

\section{Chemical Characteristics}

Bulk Chemistry 
A number of small interior fragments of about $0.5 \mathrm{~g}$ free of fusion crust were provided for chemical characterization. The results summarized in Table 3 and shown in Fig. 6 indicate that the chemical composition of Stubenberg is close to the composition of Chelyabinsk (Righter et al., 2015) and that the Stubenberg chondrite is not chemically anomalous.

\section{Noble gases}

Noble gas results for the two interior fragments of Stubenberg sample M1h (described here as Stubenberg I and II) are summarized in Table 4. All noble gases can be explained with a mixture of cosmogenic, radiogenic, and a very small amount of heavy (Ar-Xe) trapped noble gases. Most importantly, Stubenberg does not contain solar wind noble gases (Fig. 7), because of the low ${ }^{4} \mathrm{He}$ and ${ }^{20} \mathrm{Ne}$ concentrations that are entirely of cosmogenic (cos) and radiogenic (rad) origin, the lack of trapped ${ }^{20} \mathrm{Ne}$, and the very small concentration of trapped (tr) ${ }^{36} \mathrm{Ar}$ (Table 4). Hence, Stubenberg cannot be a regolith breccia.

The heavier noble gases are all meteoritic, as shown with the (low) heavy element ratios ${ }^{36} \mathrm{Ar}_{\mathrm{tr}} /{ }^{132} \mathrm{Xe}$ (=20 and 38, respectively) and ${ }^{84} \mathrm{Kr} /{ }^{132} \mathrm{Xe}(=0.78$ and 0.74$)$, and the high ${ }^{40} \mathrm{Ar} /{ }^{36} \mathrm{Ar}$ $(=3900$ and 4100$)$ and ${ }^{129} \mathrm{Xe} /{ }^{132} \mathrm{Xe}(=1.90$ and 1.95$)$ ratios.

We used the depth- and chemistry-dependent model by Leya and Masarik (2009) to determine the cosmic ray exposure (CRE) age of Stubenberg, assuming a simple " $4 \pi$ " irradiation in space and taking into account the bulk chemistry for Stubenberg given in this work (Table 3). Using the LL chemistry that is given in the Leya and Masarik (2009) data tables yields the same results. We did not re-normalize the radii according to density. All radii in the Leya and Masarik work are given for meteoroids with a density of $3.50 \mathrm{~g} / \mathrm{cm}^{3}$. The typical LL meteorite density might be $3.29 \mathrm{~g} / \mathrm{cm}^{3}$ (Wilkison and Robinson, 2000), which would increase all radii by $6 \%$. However, we do not exactly know the bulk density of the Stubenberg meteoroid, i.e. cannot take into account possible macroporosity.

The measured ${ }^{3} \mathrm{He}$ and ${ }^{21} \mathrm{Ne}$ concentrations are entirely cosmogenic, the ${ }^{38} \mathrm{Ar}$ is corrected for 2 and $4 \%$ trapped ${ }^{38} \mathrm{Ar}$, respectively (see Table 4 for details). As Ne is entirely cosmogenic, the measured ${ }^{22} \mathrm{Ne} /{ }^{21} \mathrm{Ne}$ ratio can be used directly as a shielding indicator. The precisely measured ${ }^{22} \mathrm{Ne} /{ }^{21} \mathrm{Ne}$ ratio in Stubenberg I of $1.0826 \pm 0.0026$ suggests a pre-atmospheric radius of $\geq 35 \mathrm{~cm}$. The pre-atmospheric mass of $600 \mathrm{~kg}$, based on fireball observations (Spurný et al., 2016), yields the same radius of $35 \mathrm{~cm}$. A higher mass within a conservative factor of two (1200 kg; radius of $\sim 45 \mathrm{~cm}$ ) would still be consistent with the noble gas data. However, these radii are incompatible with short-lived radionuclide data, which suggest a smaller radius. As 
discussed later, both data sets can be brought into agreement, if the Stubenberg meteoroid experienced a recent collision which decreased its radius. In the Leya and Masarik model, we hence average the cosmogenic ${ }^{3} \mathrm{He},{ }^{21} \mathrm{Ne}$, and ${ }^{38} \mathrm{Ar}$ production rates for all "allowed" sample depths for meteoroids with 35 to $50 \mathrm{~cm}$ radius, i.e. where the predicted ${ }^{22} \mathrm{Ne} /{ }^{21} \mathrm{Ne}$ matches the measured one within uncertainty. The most likely shielding depth would then be $10-12 \mathrm{~cm}$ for the samples analyzed here (Leya and Masarik, 2009). The "uncertainty" of the resulting production rates given in Table 4 covers the maximum and minimum values obtained for all allowed conditions. Note that systematic uncertainties of the Leya and Masarik (2009) production rate model, assumed to be $\sim 15-20 \%$ are not included in the uncertainties given in Table 4.

Data points of both samples plot close to or above the "Bern line" in ${ }^{3} \mathrm{He} /{ }^{21} \mathrm{Ne}$ vs. ${ }^{22} \mathrm{Ne} /{ }^{21} \mathrm{Ne}$ space (see, e.g., Fig. 5 of Scherer et al., 1998) suggesting that Stubenberg did not lose cosmogenic ${ }^{3} \mathrm{He}$ during its travel to Earth.

\section{Radionuclides}

The activities for the very short-lived radionuclides are given in Table 5 and the naturally occurring radionuclides (Table S3) are in agreement with the average concentrations in ordinary LL chondrites (Wasson and Kallemeyn, 1988).

\section{Oxygen isotopes}

The oxygen isotope composition of the analyzed fragment of Stubenberg is $\delta^{17} \mathrm{O}=3.854 \%$ and $\delta^{18} \mathrm{O}=5.067 \%$ (Figs. S3 and 8 ). This gives an offset in $\delta^{17} \mathrm{O}$ of $\Delta^{, 17} \mathrm{O}=1.216 \%$ relative to a reference line with a slope of 0.5305 that passes through San Carlos olivine $\left(\Delta^{17} \mathrm{O}=0 \%\right)$. The data for Stubenberg are consistent with those of other LL chondrites.

\section{Titanium isotopes}

The Ti isotope compositions of Stubenberg measured in Münster $\left(n=12 ; \varepsilon^{46} \mathrm{Ti}=-0.08 \pm 0.11\right.$, $\varepsilon^{48} \mathrm{Ti}=-0.05 \pm 0.11, \varepsilon^{50} \mathrm{Ti}-0.67 \pm 0.09$; all uncertainties are $95 \%$ c.i. $)$ and Zurich $\left(\mathrm{n}=7 ; \varepsilon^{46} \mathrm{Ti}\right.$ $\left.=-0.10 \pm 0.10, \varepsilon^{48} \mathrm{Ti}=0.00 \pm 0.03, \varepsilon^{50} \mathrm{Ti}-0.81 \pm 0.09\right)$ are within uncertainty identical to each other, and agree within error with literature values for ordinary chondrites (Trinquier et al., 2009; Zhang et al., 2012; Williams, 2015) (Fig. S4). 


\section{Chromium isotopes}

The $\mathrm{Cr}$ isotope composition of Stubenberg is $\varepsilon^{53} \mathrm{Cr}=0.428 \pm 0.027$ and $\varepsilon^{54} \mathrm{Cr}=-0.167 \pm 0.063$. The composition of $\varepsilon^{53} \mathrm{Cr}$ is $\sim 8 \mathrm{ppm}$ higher than the previously highest value for ordinary chondrite (OC), while the $\varepsilon^{54} \mathrm{Cr}$ value is within the range of previously reported $\mathrm{OC}$ compositions (e.g., Jenniskens et al., 2014; see Fig. 8). Although the $\mathrm{Cr}$ isotope composition of Stubenberg is on the extreme of the OC data array its composition falls within the OC region when compared with other meteorite groups.

\section{Solvent-soluble organic matter}

The analysis of the methanol-soluble organic fraction of Stubenberg by ultrahigh resolution mass spectrometry was undertaken in less than 24 hours after the fragment was found on the field and in less than one week after its fall. For details on the significance of the analysis see Ruf et al. (2017). Care was taken with respect to differentiate indigenous organic matter and possible terrestrial contamination by analyzing corresponding solvent methanolic blanks (Schmitt-Kopplin et al., 2010). The main characteristics of the compositional space was a high density of $\mathrm{m} / \mathrm{z}$ signals (higher than 60 at each nominal mass) over a mass range from 150 to $650 \mathrm{amu}$ (Fig. 9). These enormous number of $\mathrm{m} / \mathrm{z}$ signals were annotated to molecular formulas with respect to $\mathrm{C}-, \mathrm{H}-, \mathrm{N}-, \mathrm{O}-, \mathrm{S}-$ and $\mathrm{Mg}$-bearing compositions. Majorly the $\mathrm{CHO}$, $\mathrm{CHOMg}$ and $\mathrm{CHNO}$ compositions rule the detected soluble organic space of the Stubenberg meteorite.

\section{Physical Characteristics}

\section{FTIR-Spectroscopy}

The analyzed polished thin sections and rough, unprepared surfaces of the Stubenberg samples show similar spectra compared with those obtained from other metamorphosed LLgroup chondrites. The FTIR spectra in the mid-infrared of polished thin sections and rough surfaces show very similar features (Figs. 10 and S5). The characteristic Christiansen Feature (CF), a reflectance minimum used to estimate bulk compositions in remote sensing (Salisbury, 1993) is at 7.9-8.1 $\mu \mathrm{m}$. The strongest Reststrahlen Band (RB) is a 'twin-peak' feature at $10.8 \mu \mathrm{m}$ and $11.3 \mu \mathrm{m}$ of two bands with comparable intensity. Further strong RB are overlapping olivine, pyroxene, and plagioclase features found at 9.1, 9.6, 10.3, and 12.0 
$\mu \mathrm{m}$, and at 13.8, 14.6, 15.6, and $16.7 \mu \mathrm{m}$ at longer wavelengths (Baldridge et al., 2009; Hamilton 2000; 2010).

At shorter wavelengths, bands at $2.9 \mu \mathrm{m}$ indicate probably adsorbed terrestrial water. Weak features at 3.4 and $3.5 \mu \mathrm{m}$ could be aliphatic $\mathrm{C}-\mathrm{H}$ stretching of $\mathrm{CH}_{2}$ and $\mathrm{CH}_{3}$. Bands at 5.7-6 $\mu \mathrm{m}$ could be also due to water, but overlap with $\mathrm{C}=\mathrm{O}$ stretching modes (Kebukawa et al., 2011).

\section{Magnetic susceptibility}

The average values for the magnetic susceptibility (MS) of the samples, corrected for mass and dimensions, are given in Table 6. The correction procedure produces consistent values over 3 orders of magnitude of the sample mass as shown in Fig. S6. For the conversion of volumetric MS instrument readings into MS the bulk density of $3.29 \mathrm{~g} / \mathrm{cm}^{3}$ was used.

The overall average of MS is about $4.800 * 10^{-9} \mathrm{~m}^{3} / \mathrm{kg}$ corresponding to $\log (\mathrm{MS})=3.68$ which places Stubenberg at the low end of the range for LL chondrites (Table 6). The 95\% confidence interval of \pm 0.03 for $\log (\mathrm{MS})$ containing both the experimental scattering and the material inhomogeneity is remarkably narrow. The variability of five measurements at different portions of the main mass (M5) is approximately the same as that of those across all samples indicating a quite homogeneous distribution of metal in the breccia.

\section{DISCUSSION}

\section{Mineralogical properties and classification of Stubenberg}

Stubenberg is a breccia based on presented results. The textures of individual fragments are highly recrystallized (Fig. 3) and only a few relic chondrules are visible in thin section (Fig. 3). These observations already point to a high metamorphic grade of the fragments within the rock. The large grain size of plagioclase and the homogeneous compositions of olivines and pyroxenes also support this. These facts clearly indicate that the fragments within Stubenberg are of type 6. Based on the mean olivine and low-Ca pyroxene compositions of $\mathrm{Fa}_{31.4}$ and $\mathrm{Fs}_{25.4}$, respectively, the rock has to be classified as an LL-group ordinary chondrite breccia. Since no fragments of other petrologic type have been observed so far a classification as a LL6 breccia is appropriate. However, Stubenberg does not belong to the complicated breccias like Almahata Sitta (e.g., Bischoff et al., 2010; Horstmann et al., 2010; Goodrich et al., 2014; Horstmann and Bischoff, 2014) or to the complex regolith breccias among the L- and LLgroup ordinary chondrites (Bischoff et al., 1993, 2013a, 2006; Metzler et al., 2010, 2011) and 
is also different to the LL5-6 breccia Chelyabinsk (Bischoff et al., 2013b; Righter et al., 2015; Morlok et al., 2017). This is consistent with the lack of solar wind implanted noble gases (Fig. 7); thus, the breccia does not contain fragmental debris that was exposed at the surface and hence has to be characterized as a fragmental breccia. This result is also consistent with the observation that no other lithologies beside type 6 fragments were encountered. Considering the onion-shell model for the setting of the parent body no clasts of lower petrologic type (35) originated from the upper areas of the parent body were mixed into the breccia during impact-induced lithification (Kieffer, 1975; Bischoff et al., 1983).

Based on the undulatory extinction in olivine and plagioclase and the presence of planar fractures in olivine, the chondrite is weakly shocked (S3). Thus, Stubenberg is an LL6, S3 ordinary chondrite breccia.

Applying the two-pyroxene thermometer implemented in the QUILF 95 program (Andersen et al., 1993) using the compositions listed in Table 2 yields an equilibration temperature of $914 \pm 44{ }^{\circ} \mathrm{C}$. This is consistent with typical values obtained from LL6 chondrites and interpreted as peak metamorphic temperatures (Slater-Reynolds and McSween, 2005). Nipoor pentlandite has been described from several equilibrated LL chondrites and the coexistence of pentlandite with troilite, kamacite, taenite, and potentially tetrataenite indicates disequilibrium among these opaque phases (Michel-Lévy and Bourot-Denise, 1992; Jamsja and Ruzicka, 2010). The low Ni content places the pentlandite outside of the typical compositional range observed in exsolved pentlandite-pyrrhotite assemblages (e.g., Jamsja and Ruzicka, 2010), but thermodynamic modelling suggests that (partial) equilibration at temperatures below $360{ }^{\circ} \mathrm{C}$ will produce Fe-rich pentlandite (Waldner and Pelton, 2004). Disregarding the Co content, the pentlandite may have last equilibrated with the troilite at a temperature of about $250{ }^{\circ} \mathrm{C}$ or below. Possibly, the sulfide assemblage was produced and incorporated during the brecciation event and internally equilibrated during cooling without significant chemical exchange with the other opaque phases of the rock.

Two different $\mathrm{TiO}_{2}$ phases (anatase and rutile) could be identified as single grains by their different Raman spectra (Fig. S2). Ramdohr (1973) proposed the following reaction concerning a likely Ti-oxide formation process in ordinary chondrites: Reduction of ilmenite in the presence of carbon phases (carbon, graphite or hydrocarbons), which have been also detected in Stubenberg (see above) to native iron and Ti-oxide according to the reaction: $2 \mathrm{FeTiO}_{3}+\mathrm{C}=2 \mathrm{Fe}+2 \mathrm{TiO}_{2}+\mathrm{CO}_{2}$. 


\section{Chemical properties of Stubenberg}

The bulk composition of the Stubenberg meteorite determined so far is very close to the published concentrations of other metamorphosed LL-group ordinary chondrites like Chelyabinsk (Table 3; Fig. 6; Righter et al., 2015). It can be concluded that no anomalies in elemental composition of the Stubenberg meteorite were detected compared with other LLchondrites. The O-, Ti-, and Cr-isotope compositions of Stubenberg are also typical of LL ordinary chondrites (Figs. 8, S3, and S4).

Exact molecular formula assignments and resulting compositional space of organic constituents show a consistent coverage of $\sim 4600$ elementary compositions. In van Krevelentype representations, the chemical space is plotted as $\mathrm{H} / \mathrm{C}$ vs $\mathrm{O} / \mathrm{C}$ ratio or m/z ratio (Fig. 9) keeping abundances of the signals in bubble sizes. This allows insights on the chemical properties on the plotted chemical compositions. Information regarding the degree of unsaturation and oxygenation about the respective chemical compositions are observed, detecting a broad range of oxygenation of mainly aliphatic compounds for the Stubenberg soluble organic matter. Compositions with higher degree of oxidation and higher number of nitrogen and sulfur could be observed, as compared to lower shock-metamorphosed ordinary chondrites (Fig. 9; Schmitt-Kopplin et al., 2012; Popova et al., 2013; Jenniskens et al., 2014). High shock-metamorphosed ordinary chondrites show higher nitrogenated chemical compounds (Popova et al., 2013; Jenniskens et al., 2014). In addition, Stubenberg showed an unusual organomagnesium space ( $\mathrm{CHOMg}$ ) with an extremly dense and complete signature with more than $1000 \mathrm{CHOMg}$ compositions, as many as $\mathrm{CHO}$ compositions. This reflects a high metamorphic temperature and a complex shock history of the parent body as explained in detail elsewhere (Ruf et al., 2017) as these thermostable metalorganic compounds could be related to the degree of thermal process of a meteorite. From the rapid results obtained on the soluble organic compositions, we conclude that Stubenberg shows characteristics consistent with the complex shock, brecciation, and lithification history of the breccia.

As expected for a freshly fallen LL6 chondrite, the noble gases do not carry significant terrestrial contamination. All precisely measurable heavier noble gas element and isotopic ratios indicate pure meteoritic rather than terrestrial noble gases. The trapped ${ }^{36} \mathrm{Ar}$, ${ }^{84} \mathrm{Kr}$, and ${ }^{132} \mathrm{Xe}$ concentrations are extremely low, consistent with Stubenberg being classified in this 
work as LL6. For example, element ratios and isotopic compositions (particularly ${ }^{40} \mathrm{Ar} /{ }^{36} \mathrm{Ar}$ and ${ }^{129} \mathrm{Xe} /{ }^{132} \mathrm{Xe}$ ) are similar to those found in LL5 Olivenza and LL6 Saint Séverin (Alaerts et al., 1979). The trapped gases that remained after thermal metamorphism are similar to phase Q gases (Busemann et al., 2000). The presence of ${ }^{129} \mathrm{Xe}$ derived from short-lived ${ }^{129} \mathrm{I}$ with a half-life of $\sim 16 \mathrm{Ma}\left({ }^{129} \mathrm{Xe} /{ }^{132} \mathrm{Xe}=1.90\right.$ and 1.95$)$ indicates closure for Xe loss within the first $\sim 100 \mathrm{Ma}$.

We obtain a most likely $4 \pi \mathrm{CRE}$ age for Stubenberg of $36 \pm 3$ Ma assuming a radius of $35-50$ $\mathrm{cm}$ (covering all shielding conditions "allowed" by the cosmogenic ${ }^{22} \mathrm{Ne} /{ }^{21} \mathrm{Ne}$ of 1.0826 determined for Stubenberg; Leya and Masarik, 2009). This age is an average of all six CRE ages obtained for both samples and the three light cosmogenic isotopes ${ }^{3} \mathrm{He},{ }^{21} \mathrm{Ne}$, and ${ }^{38} \mathrm{Ar}$ (Table 4). This age is typical for a large fraction of LL chondrites with CRE ages around 30 Ma (e.g., Scherer et al., 1998; Fig. 4 in Herzog and Caffee, 2014). Much larger preatmospheric radii, while still possible using noble gas systematics alone, might not be likely, based on the pre-atmospheric mass of $600 \mathrm{~kg}$ as estimated with fireball observations (Spurný et al., 2016).

The remarkable agreement between all CRE ages (Table 4) suggests no preferred He loss due to heating in space (as a possible result of the meteoroid's passage close to the Sun), or during atmospheric entry, which could cause preferential He loss. This observation allows us to also determine gas retention ages for Stubenberg, unaffected by late reset, after ejection from the LL parent body. Using the K, U and Th concentrations determined in this work (Table 3), we obtain nominal (maximum) U/Th- ${ }^{4} \mathrm{He}$ ages of $\sim 3.0 \mathrm{Ga}$ and $\mathrm{K}-{ }^{40} \mathrm{Ar}$ ages of $\sim 4.1 \mathrm{Ga}$ (Table 4). The measured $U$ concentration of $6.3 \mathrm{ppm}$ appears somewhat low (Table 3). If we use a more typical U concentration of 13 ppm (e.g., Wasson and Kallemeyn, 1988), the U/Th- ${ }^{4} \mathrm{He}$ ages would be around $2.2 \mathrm{Ga}$.

Such gas-retention ages can be determined under the assumption that significant partial loss after the calculated closure to gas loss did not occur. Such nominal ages have been observed for LL chondrites before, and show generally that the material of Stubenberg has not been shocked severely late in the LL chondrite parent body's history.

${ }^{26} \mathrm{Al}$ (Leya and Masarik, 2009), ${ }^{60} \mathrm{Co}$ (Eberhardt et al., 1963; Spergel et al., 1986), ${ }^{54} \mathrm{Mn}$ (Kohman and Bender, 1967), and ${ }^{22} \mathrm{Na}$ (Bhandari et al., 1993) give as possible size range of the parent body (in the sequence of the given isotopes) radii of $20-120 \mathrm{~cm},<20 \mathrm{~cm}, 10-126$ $\mathrm{cm}$, and $15-100 \mathrm{~cm}$. Combining all results of these radionuclides we infer a roughly spherical 
meteoroid with $<20 \mathrm{~cm}$ radius, mainly due to the very small value of ${ }^{60} \mathrm{Co}$. This estimate is further confirmed by the fact that the values for both specimens, so different in size, are similar (see Bhandari et al., 1993). The ${ }^{22} \mathrm{Na} /{ }^{26} \mathrm{Al}$ of $(1.5+-0.2)$ is close to the average value for LL chondrites (Bhandari et al., 2002).

The fall of the Stubenberg LL6 chondrite occurred during the current solar cycle 24 maximum, as indicated by the neutron monitor data (Bartol, 2016). The cosmic ray flux was low in the six months before the fall. As a result, the activities for the very short-lived radionuclides are expected to be low (see Table 5), similar to the earlier reported data for Jesenice (Bischoff et al., 2011 and references cited therein). The naturally occurring radionuclides (Table S3) are in agreement with the average concentrations in ordinary LL chondrites (Wasson and Kallemeyn, 1988).

The calculated difference in radius resulting from short-lived radionuclides $(<20 \mathrm{~cm})$ and noble gases $(>35 \mathrm{~cm})$ could be explained if Stubenberg experienced a complex exposure history, in which most of the cosmogenic noble gases were produced in a $>35 \mathrm{~cm}$ object in space, before a collision reduced the meteoroid size to $<20 \mathrm{~cm}$. Since the ${ }^{26} \mathrm{Al}$ data are consistent with a larger (20-120 cm radius; Leya and Masarik, 2009) object, the change in radius would have to have happened within no more than a few half-lives of ${ }^{26} \mathrm{Al}\left(\mathrm{t}_{1 / 2}=717\right.$ ka). A complex exposure history for Stubenberg would also seem likely because its CRE age is a factor 3-4 longer than the typical time such a small meteoroid is likely to escape collisional disruption in the asteroid belt, of 9 and $12 \mathrm{Ma}$ for an $\mathrm{R}=20 \mathrm{~cm}$ and $\mathrm{R}=35 \mathrm{~cm}$ stony meteoroid, respectively (Farinella et al., 1998). However, there is an additional discrepancy between the size of Stubenberg as implied by short-lived radionuclides $(<20 \mathrm{~cm})$ and the estimated mass of the meteoroid implied from fireball observations (ca. $600 \mathrm{~kg}, \mathrm{R} \sim 35$ cm; Spurný et al., 2016). This could potentially be resolved if the Stubenberg meteoroid had a significant macroporosity: as the cosmic-ray-induced production of cosmogenic noble gases and radionuclides depends on the product of radius and density, a lower bulk density would result in a larger physical radius and thus a much larger mass (since $M \sim R^{3}$; see Welten et al., 2010). At a fragment density of $3.29 \mathrm{~g} / \mathrm{cm}^{3}$ and a macroporosity of $50 \%$, a meteoroid with a size consistent with the measured ${ }^{60} \mathrm{Co}$ activity would have a mass of $\sim 530 \mathrm{~kg}$, consistent with the mass from the fireball estimate. More detailed modeling of the entry fireball, which is beyond the scope of this paper, will be required to resolve this discussion. 


\section{Physical properties of Stubenberg}

The analyzed polished thin sections and rough, unprepared surfaces of the Stubenberg samples show similar spectra compared with those obtained from other metamorphosed LLgroup chondrites (Figs. 10 and S5), Tuxtuac (LL5) and Paragould (LL6). These spectra were acquired by investigators Carle Pieters and Jitendra N. Goswami with the NASA RELAB facility at Brown University. They show essentially similar RB features at 9.5-9.6, 10.3, 10.8 and 11.2-11.3 $\mu \mathrm{m}$ as Stubenberg, while the CF is clearly shifted with $8.6 \mu \mathrm{m}$ compared to 8.0$8.1 \mu \mathrm{m}$ for Stubenberg, indicating a lower content in crystallized mesostasis feldspar (Fig. 10) (Salisbury, 1993).

The comparison of the FTIR data with that of heavily shocked LL6 chondrite Chelyabinsk (Morlok et al., 2017) shows a high similarity in band positions and band shapes with the moderately-shocked lithology (Fig. 10). In addition to the four strong bands between 9.6 and $11.3 \mu \mathrm{m}$, which are also visible in the moderately-shocked lithology of Chelyabinsk, Stubenberg also has a clear feature at $9.1 \mu \mathrm{m}$, which is only visible as a shoulder in the Chelyabinsk samples. Shock-darkened and impact melt lithologies show a decrease in feature intensities and loss of bands. This implies a low degree of impact shock of the bulk Stubenberg material. Features visible in the 5.7-6.0 $\mu \mathrm{m}$ range occurring in the Chelyabinsk sample are only very weak in Stubenberg. This is most probably due to the differences in sample preparation, where the powdered Chelyabinsk material provided higher surface area resulting in stronger minor features compared to the surfaces analyzed of Stubenberg in this work.

The measured magnetic susceptibility data support the classification of Stubenberg as an LL chondrite. Comparing the average values of LL group members given in Rochette et al. (2003) and Macke (2010) the Stubenberg value is significantly lower than the data of LL3 to LL6 meteorites. On the other hand, regarding the limits of variation in the different groups, Stubenberg might fit into LL4 to LL6, with a tendency towards the very special LL7 group (however, represented only by one measured fall, Uden) with a still lower susceptibility value (3.33).

\section{CONCLUSION}

Stubenberg fell on March 6, 2016 and the first pieces were recovered six days later after an exact calculation of the impact area based on instrumental observations taken by the six cameras of the Czech part of the European Fireball Network. Altogether six individuals 
weighing in total $1473 \mathrm{~g}$ were recovered. It is classified as an LL6, S3 ordinary chondrite fragmental breccia. The bulk composition of the Stubenberg meteorite is very close to element concentrations of other metamorphosed LL-group ordinary chondrites. This is also consistent with $\mathrm{O}-$, $\mathrm{Ti}-$, and $\mathrm{Cr}$-isotope data and IR spectroscopy.

The measured activities of short-lived cosmogenic radionuclides clearly indicate that the analyzed pieces result from a very recent meteorite fall consistent with the Stubenberg fall. A cosmic ray exposure (CRE) age of $36 \pm 3$ Ma has been obtained for the meteoroid. Using the $\mathrm{K}$, U, and Th concentrations determined in this work nominal (maximum) $\mathrm{U} / \mathrm{Th}-{ }^{4} \mathrm{He}$ ages of $\sim 3.0 \mathrm{Ga}$ and $\mathrm{K}-{ }^{40} \mathrm{Ar}$ ages of $\sim 4.1 \mathrm{Ga}$ are determined. 
Acknowledgements: We thank U. Heitmann (Münster) and M. Lippold (Jena) for sample preparation. Christian Rewitzer (München) is thanked by one of the authors (RH) for making his scanning electron microscope available for investigations of the Stubenberg meteorite. We thank C. Corrigan, an anonymous reviewer, and the Associate Editor Ed Scott for their fruitful comments and suggestions. The SEM-FIB-TEM facility at the Universität Jena is funded by the DFG (grant LA 830/14-1), F. Langenhorst is thanked for support of the work conducted at the facility. The work of P. Spurný was supported by Praemium Academiae from the Czech Academy of Sciences. M. M., K. B., and M. S. thank the Swiss National Science Foundation (SNF) for support. A.B. and S.E. thank the DFG for support within the SFB-TRR 170 "Late Accretion onto Terrestrial Planets" (subproject B5; AB). This is TRR 170 publication No. 23. This is contribution 5322 of the University of Maryland Center for Environmental Science. The samples were donated by Michael Krippner, Michael Gonsior, Dennis Harries, Ralph Sporn and Martin Neuhofer. This is greatly acknowledged. 


\section{REFERENCES}

Alaerts L., Lewis R. S., and Anders E. 1979. Isotopic anomalies of noble gases in meteorites and their origins - III. LL-chondrites. Geochim. Cosmochim. Acta 43:1399-1415.

Andersen D. J., Lindsley D. H., and Davidson P. M. 1993. QUILF: A pascal program to assess equilibria among Fe-Mg-Mn-Ti oxides, pyroxenes, olivine, and quartz. Computers \& Geosciences 19:1333-1350.

Arpesella C. 1996. A low background counting facility at Laboratori Nazionali del Gran Sasso. Appl. Radiation Isotopes 47:991-996.

Baldridge A. M., Hook S. J., Grove C. I., and Rivera G. 2009. The ASTER Spectral Library Version 2.0. Remote Sensing of Environment 113:711-715.

Barrat J.-A., Zanda B., Moynier F., Bollinger C., Liorzou C., and Bayron G. 2012. Geochemistry of CI chondrites: Major and trace elements, and $\mathrm{Cu}$ and $\mathrm{Zn}$ isotopes. Geochimica et Cosmochimica Acta 83:79-92.

Barrat J.-A., Rouxel O., Wang K., Moynier F., Yamaguchi A., Bischoff A., and Langlade J. 2015. Early stages of core segregation recorded by Fe isotopes in an asteroidal mantle. Earth Planet. Sci. Lett. 419:93-100.

Barrat J.-A., Gillet P., Dauphas N., Bollinger C., Etoubleau J., Bischoff A., and Yamaguchi A. 2016. Evidence from Tm anomalies for non-CI refractory lithophile element proportions in terrestrial planets and achondrites. Geochim. Cosmochim. Acta. 176:117.

Bartol Neutron Monitors. 2016. http://neutronm.bartol.udel.edu/

Bartoschewitz R., Appel P., Barrat J.-A., Bischoff A., Caffee M. W., Franchi I. A., Gabelica Z., Greenwood R. C., Harir M., Harries D., Hochleitner R., Hopp J., Laubenstein M., Mader B., Marques R., Morlok A., Nolze G., Prudêncio M. I., Rochette P., Ruf A., Schmitt-Kopplin Ph, Seemann E., Szurgot M., Tagle R., Wach R. A., Welten K. C., Weyrauch M., and Wimmer K. 2017. The Braunschweig meteorite - a recent L6 chondrite fall in Germany. Chemie der Erde - Geochemistry; http://dx.doi.org/10.1016/j.chemer.2016.10.004

Bhandari N., Mathew K. J., Rao M. N., Herpers U., Bremer K., Vogt S., Wölfli W., Hofmann H. J., Michel R., Bodemann R., and Lange H.-J. 1993. Depth and size dependence of 
cosmogenic nuclide production rates in stony meteoroids. Geochimica Cosmochimica Acta 57:2361-2375.

Bhandari N., Murty S. V. S., Shukla P. N., Shukla A. D., Mahajan R. R., Sarin M. M., Srinivasan G., Suthar K. M., Sisodia M. S., Jha S., Bischoff A. 2002. Itawa Bhopji (L3-5) chondrite regolith breccia: Fall, classification and cosmogenic records. Meteoritics \& Planetary Science, 37:549-563.

Bischoff A. and Stöffler D. 1992. Shock metamorphism as a fundamental process in the evolution of planetary bodies: Information from meteorites. Europ. J. Mineral. 4:707755.

Bischoff A., Rubin A. E., Keil K., and Stöffler D. 1983. Lithification of gas-rich chondrite regolith breccias by grain boundary and localized shock melting. Earth Planet. Sci. Lett. 66:1-10.

Bischoff A., Geiger T., Palme H., Spettel B., Schultz L., Scherer P., Schlüter J., and Lkhamsuren J. 1993. Mineralogy, chemistry, and noble gas contents of Adzhi-Bogdo an LL3-6 chondritic breccia with foreign clasts. Meteoritics 28:570-578.

Bischoff A., Jersek M., Grau T., Mirtic B., Ott U., Kučera J., Horstmann M., Laubenstein M., Herrmann S., Randa Z., Weber M., and Heusser G. 2011. Jesenice - A new meteorite fall from Slovenia. Meteoritics \& Planetary Science 46:793-804.

Bischoff A., Scott E. R. D., Metzler K., and Goodrich C. A. 2006. Nature and Origins of meteoritic breccias. Book chapter in "Meteorites and the Early Solar System II" (eds. D.S. Lauretta and H.Y. McSween Jr.), 679-712, Univ. of Arizona, Tucson.

Bischoff A., Horstmann M., Pack A., Laubenstein M., and Haberer S. 2010. Asteroid 2008 $\mathrm{TC}_{3}$ - Almahata Sitta: A spectacular breccia containing many different ureilitic and chondritic lithologies. Meteoritics \& Planetary Science 45:1638-1656.

Bischoff A., Dyl K. A., Horstmann M., Ziegler K., Wimmer K., and Young E. D. 2013a. Reclassification of Villalbeto de la Peña - occurrence of a winonaite-related fragment in a hydrothermally metamorphosed polymict L-chondritic breccias. Meteoritics \& Planetary Science 48:628-640.

Bischoff A., Horstmann M., Vollmer C., Heitmann U., and Decker S. 2013b. Chelyabinsk not only another ordinary LL5 chondrite, but a spectacular chondrite breccia (abstract No. 5171). Meteoritics \& Planetary Science 48:A61. 
Busemann H., Baur H., and Wieler R. 2000. Primordial noble gases in "phase Q" in carbonaceous and ordinary chondrites studied by closed-system stepped etching. Meteoritics \& Planetary Science 35:949-973.

Busemann H., Toth E. R., Clay P. L., Gilmour J. D., Nottingham M., Strashnov I., Wieler R., Nishiizumi K., and Jones R. H. 2014. Noble gases in the LL5 chondrite Chelyabinsk. Lunar Planet. Sci. Conf. 45, \#2805.

Clayton R. N. and Mayeda T. K. 1984. Oxygen isotopic compositions of enstatite chondrites and aubrites. JGR, J. Geophys. Res. (Sect.) C 89 (15).

Clayton R. N. and Mayeda, T. K. 1996. Oxygen isotope studies of achondrites. Geochimica et Cosmochimica Acta 60:1999 - 2017.

Clayton R. N. and Mayeda T. K. 1999. Oxygen isotope studies of carbonaceous chondrites. Geochimica et Cosmochimica Acta 63:2089-2104.

Clayton R., Mayeda T., Olsen E., and Goswami J. 1991. Oxygen isotope studies of ordinary chondrites. Geochimica et Cosmochimica Acta 55:2317-2337

Eberhardt P., Geiss J., and Lutz H. 1963. Neutrons in meteorites. In Earth Science and Meteoritics, edited by Geiss, J. and Goldberg, E. D. Amsterdam: North Holland Publ. Co., 143-168.

Ebert S. and Bischoff A. 2016. The Stubenberg (Bavaria) ordinary chondrite breccia: The latest German meteorite fall. Meteoritics \& Planetary Science 51, Special Issue, \#6137.

Eugster O., Michel T., Niedermann S., Wang D., and Yi W. 1993. The record of cosmogenic, radiogenic, fissiogenic, and trapped noble gases in recently recovered Chinese and other chondrites. Geochim. Cosmochim. Acta 57:1115-1142.

Farinella P., Vokrouhlický D., and Hartmann W. K. 1998. Meteorite delivery via Yarkovsky orbital drift. Icarus 132:378-387

Goodrich C. A., Bischoff A., and O'Brien D. P. 2014. Asteroid $2008 \mathrm{TC}_{3}$ and the fall of Almahata Sitta, a unique meteorite breccia. Elements 10:31-37.

Hamilton V.E. 2000. Thermal infrared emission spectroscopy of the pyroxene mineral series. Journal of Geophysical Research 105:9701-9716 
Hamilton V.E. 2010. Thermal infrared (vibrational) spectroscopy of Mg-Fe olivines: A review and applications to determining the composition of planetary surfaces. Chemie der Erde - Geochemistry 70:7-33.

Harries D., and Langenhorst F. 2013. The nanoscale mineralogy of Fe,Ni sulfides in pristine and metamorphosed $\mathrm{CM}$ and $\mathrm{CM} / \mathrm{CI}$-like chondrites: Tapping a petrogenetic record. Meteoritics and Planetary Science 48:879-903.

Heber V. S., Wieler R., Baur H., Olinger C., Friedmann T. A., and Burnett, D. S. 2009. Noble gas composition of the solar wind as collected by the Genesis Mission. Geochim. Cosmochim. Acta 73:7414-7432.

Hertkorn N., Harir M., and Schmitt-Kopplin Ph. 2015. Nontarget analysis of Murchison soluble organic matter by high-field NMR spectroscopy and FTICR mass spectrometry. Magnetic Resonance Chemistry 53:754-768.

Herzog G. F. and Caffee M. (2014) Cosmic-ray exposure ages of meteorites. In Treatise on Geochemistry 2nd ed. - Vol. 2 Planets, Asteroids, Comets and The Solar System (ed. A. M. Davies), pp. 419-453. Elsevier.

Heusser G., Weber M., Hakenmüller J., Laubenstein M., Lindner M., Maneschg W., Simgen H., Stolzenburg D. and Strecker H. 2015. GIOVE: a new detector setup for high sensitivity germanium spectroscopy at shallow depth. The European Physical Journal C75:531.

Heymann D. and Mazor E. 1966, St. Mesmin, a gas-rich amphoteric chondrite. J. Geophys. Res. 71:4695-4697.

Horstmann M. and Bischoff A. 2014. The Almahata Sitta polymict breccia and the late accretion of Asteroid $2008 \mathrm{TC}_{3}$ - Invited Review. Chemie der Erde - Geochemistry 74:149-184.

Horstmann M., Bischoff A., Pack A., and Laubenstein M.: Almahata Sitta - fragment MS-CH: Characterization of a new chondrite type. 2010. Meteoritics \& Planetary Science 45:1657-1667.

Jamsja N., and Ruzicka A. 2010. Shock and thermal history of Northwest Africa 4859, an annealed impact-melt breccia of LL chondrite parentage containing unusual igneous features and pentlandite. Meteoritics \& Planetary Science 45:828-849. 
Jenniskens, P., Rubin, A. E., Yin, Q.-Z., Sears, D. W. G., Sandford, S. A., Zolensky, M. E., Krot, A. N., Blair, L., Kane, D., Utas, J., Verish, R., Friedrich, J. M., Wimpenny, J., Eppich, G. R., Ziegler, K., Verosub, K. L., Rowland, D. J., Albers, J., Gural, P. S., Grigsby, B., Fries, M. D., Matson, R., Johnston, M., Silber, E., Brown, P., Yamakawa, A., Sanborn, M. E., Laubenstein, M., Welten, K. C., Nishiizumi, K., Meier, M. M. M., Busemann, H., Clay, P., Caffee, M. W., Schmitt-Kopplin, P., Hertkorn, N., Glavin, D. P., Callahan, M. P., Dworkin, J. P., Wu, Q., Zare, R. N., Grady, M., Verchovsky, S., Emel'Yanenko, V., Naroenkov, S., Clark, D. L., Girten, B., Worden, P. S., Consortium), T. N. M. 2014. Fall, recovery, and characterization of the Novato L6 chondrite breccia. Meteoritics \& Planetary Science 49:1388-1425.

Kebukawa Y., Alexander C. M. O’D., and Cody G. D. 2011. Compositional diversity in insoluble organic matter in type 1, 2 and 3 chondrites as detected by infrared spectroscopy. Meteoritics \& Planetary Science 75:3530-3541.

Kieffer S. W. 1975. From regolith to rock by shock. The Moon 13:301-320.

Kohman T. P. and Bender M. L. 1967. Nuclide production by cosmic rays in meteorites and on the Moon. High-Energy Nuclear Reactions in Astrophysics. In: High-Energy Nuclear Reactions in Astrophysics - A collection of articles. Edited by Shen B. S. P. and Benjamin W. A., New York. N.Y. pp. 169-245.

Leya I. and Masarik J. 2009. Cosmogenic nuclides in stony meteorites revisited. Meteoritics \& Planetary Sciences 44:1061-1086.

Macke R. J. 2010. Survey of meteorite physical properties: density, porosity and magnetic susceptibility. PhD Thesis, Univ. Central Florida, Orlando.

Metzler K., Bischoff A., Palme H., and Gellissen: Impact melt rocks from the L3-6 chondritic regolith breccia Northwest Africa (NWA) 869. 2010. Meteoritics \& Planetary Science 45:A137.

Metzler K., Bischoff A., Greenwood R. C., Palme H., Gellissen M., Hopp J., Franchi I. A., and Trieloff M. 2011. The L3-6 chondritic regolith breccia Northwest Africa (NWA) 869: (I) Petrology, chemistry, oxygen isotopes, and Ar-Ar age determinations. Meteoritics \& Planetary Science 46:652-680.

Michel-Levy M. C., and Bourot Denise M. 1992. Dahmani, a highly oxidised LL6 chondrite bearing Ni-rich taenite. Meteoritics 27:184-185. 
Morlok A., Bischoff A., Patzek M., Sohn M., and Hiesinger H. 2016. Chelyabinsk - a rock with many different (stony) faces: An infrared study. Icarus 284: 431-442 (2017)

Niederer F. R., Papanastassiou D. A., and Wasserburg G. J., 1981. The isotopic composition of titanium in the Allende and Leoville meteorites. Geochimica et Cosmochimica Acta 45:1017-1031.

Pack A., Tanaka R., Hering M., Sengupta S., Peters S., and Nakamura E. 2016. The oxygen isotope composition of San Carlos olivine on VSMOW2-SLAP2 scale. Rapid Commun. Mass Spectrom. 30:1495-1504.

Popova O. P., Jenniskens P., Emelyanenko V., Kartashova A., Biryukov E., Khaibrakhmanov S., Shuvalov V., Rybnov Y., Dudorov A., Grokhovsky V. I., Badyukov D. D., Yin Q.Z., Gural P. S., Albers J., Granvik M., Evers L. G., Kuiper J., Kharlamov V., Solovyov A., Rusakov Y. S., Korotkiy S., Serdyuk I., Korochantsev A. V., Larionov M. Y., Glazachev D., Mayer A. E., Gisler G., Gladkovsky S. V., Wimpenny J., Sanborn M. E., Yamakawa A., Verosub K. L., Rowland D. J., Roeske S., Botto N. W., Friedrich J. M., Zolensky M. E., Le L., Ross D., Ziegler K., Nakamura T., Ahn I., Lee J. I., Zhou Q., Li X.-H., Li Q.-L., Liu Y., Tang G.-Q., Hiroi T., Sears D., Weinstein I. A., Vokhmintsev A. S., Ishchenko A. V., Schmitt- Kopplin P., Hertkorn N., Nagao K., Haba M. K., Komatsu M., and Mikouchi T. 2013. Chelyabinsk airburst, damage assessment, meteorite recovery, and characterization. Science 342:1069-1073.

Qin L., Alexander C. M. O., Carlson R. W., Horan M. F., and Yokoyama T. 2010. Contributors to chromium isotope variation of meteorites. Geochimica et Cosmochimica Acta 74:1122-1145.

Ramdohr P. 1973. The opaque minerals in stony meteorites. Elsevier Publishing Company Amsterdam, London, New York, 245 pp.

Riebe M. E. I., Welten K., Meier M. M. M., Wieler R., Bart M. I. F., Ward D., Laubenstein M., Bischoff A., Caffee M. W., Nishiizumi K., and Busemann H. 2017. Cosmic-ray exposure ages of six chondritic Almahata Sitta fragments. Meteoritics \& Planetary Science (in revision)

Righter K., Abell P., Agresti D., Berger E.L., Burton A.S., Delaney J.S., Fries M.D., Gibson E.K., Haba M.K., Harrington R., F. Herzog G. F., Keller L. P., Locke D., Lindsay F. N., McCoy T. J., Morris R. V., Nagao K., Nakamura-Messenger K., Niles P. B., Nyquist L. E., 
Park J., Peng Z. X., Shih C.-Y., Simon J. I., Swisher III C.C., Tappa M. J., Turrin B. D., and Zeigler R. A. 2015. Mineralogy, petrology, chronology, and exposure history of the Chelyabinsk meteorite and parent body. Meteoritics \& Planetary Science 50:17901819.

Rochette P., Sagnotti L., Bourot-Denise M., Consolmagno G., Folco L., Gattacceca J., Osete M. L., and Pesonen L. 2003. Magnetic classification of stony meteorites: 1. Ordinary chondrites. Meteoritics \& Planetary Science 38:251-268.

Ruf A., Kanawati B., Hertkorn N., Yin Q. Z., Moritz F., Harir M., Lucio M., Michalke B., Wimpenny J., Shilobreeva S., Bronsky B., Saraykin V., Gabelica Z., Gougeon R., Quirico E., Ralew S., Jakubowski T., Haack H., Jenniskens P., N.W. Hinman and Schmitt-Kopplin Ph. 2017. Previously unknown class of metalorganic compounds revealed in meteorites, Proceedings of the National Academy of Sciences, doi: $10.1073 /$ pnas. 1616019114

Rumble D., Zolensky M. E., Friedrich J. M., Jenniskens P., and Shaddad M. H. 2010. The oxygen isotope composition of Almahata Sitta. Meteoritics \& Planetary Science 45:1765-1770.

Salisbury J. W. 1993. Mid-Infrared Spectroscopy: Laboratory Data. In: Remote Geochemical Analysis: Elemental and Mineralogical Composition, Eds: C.M.Pieters and P.A.J. Englert. Cambridge University Press.

Scherer P., Herrmann S., and Schultz L. (1998) Noble gases in twenty-one Saharan LLchondrites: Exposure ages and possible parings. Meteoritics \& Planetary Science $33: 259-265$.

Schmitt-Kopplin Ph., Gabelica Z., Gougeon R.D., Fekete A., Kanawati B., Harir M., Gebefuegi I., Eckel G., and Hertkorn N. 2010. High molecular diversity of extraterrestrial organic matter in Murchison meteorite revealed 40 years after its fall. PNAS, 107(7):2763-2768.

Schmitt-Kopplin Ph., Harir M., Kanawati B., Tziotis D., Hertkorn N., and Gabelica Z. 2012. Chemical footprint of the solvent soluble extraterrestrial organic matter occluded in Sołtmany ordinary chondrite, Meteorite Journal, Special issue Soltmany, 1-2:79-92. 
Schönbächler M., Rehkämper M., Lee D.-C., and Halliday A. N. 2004. Ion exchange chromatography and high precision isotopic measurements of zirconium by MC-ICPMS. Analyst 129:32-37.

Schultz L. and Franke L. 2004. Helium, neon, and argon in meteorites: A data collection. Meteorit. Planet. Sci. 39:1889-1890.

Sharp Z. D. 1990. A laser-based microanalytical technique for in situ determination of oxygen isotope ratios of silicates and oxides, Geochim. Cosmochim. Acta 54:1353-1357.

Shukolyukov A. and Lugmair G. W. 2006. Manganese-chromium isotope systematics of carbonaceous chondrites. Earth and Planetary Science Letters 250:200-213.

Slater-Reynolds V. and McSween H. Y. 2005. Peak metamorphic temperatures in type 6 ordinary chondrites: An evaluation of pyroxene and plagioclase geothermometry. Meteoritics \& Planetary Science 40:745-754.

Spergel M. S., Reedy R. C., Lazareth O. W., Levy P. W., and Slatest L. A. 1986. Cosmogenic neutron-capture-produced nuclides in stony meteorites. $16^{\text {th }}$ Proceedings of the Lunar \& Planetary Science Conference. Journal of Geophysical Research Supplement 91:D483-D494.

Spurný P., Borovička J., and Shrbený L. 2007. Automation of the Czech part of the European fireball network: equipment, methods and first results. In Near Earth Objects, our Celestial Neighbors: Opportunity and Risk (A. Milani, G.B. Valsecchi \& D. Vokrouhlický, eds.) IAU Symposium, 236:121-130

Spurný P., Borovicka J., Haloda J., Shrbeny L., and Heinlein D. 2016. Two very precisely instrumentally documented meteorite falls: Žd'ár nad Sázavou and Stubenberg prediction and reality. Meteoritics \& Planetary Science 51, Special Issue, \# 6221.

Steele R. C. J., Schönbächler M. 2016. High precision mass-independent Cr isotope compositions by MC-ICPMS and MC-TIMS: application to terrestrial and meteorite samples. Goldschmidt abstract, \#2947.

Stöffler D., Keil D., and Scott E. R. D. 1991. Shock metamorphism of ordinary chondrites. Geochimica et Cosmochimica Acta 55:3845-3867.

The Meteoritical Bulletin, No. 105. 2016, in preparation 
Trinquier A., Birck J. L., Allègre C. J., Göpel C., and Ulfbeck D. $2008 .{ }^{53} \mathrm{Mn}-{ }^{53} \mathrm{Cr}$ systematics of the early Solar System revisited. Geochimica et Cosmochimica Acta 72:5146-5163.

Trinquier A., Elliott T., Ulfbeck D., Coath C., Krot A.N., and Bizzarro M. 2009. Origin of nucleosynthetic isotope heterogeneity in the solar protoplanetary disk. Science 324:374-376.

Tziotis D., Hertkorn N., and Schmitt-Kopplin, Ph. 2011. Kendrick-analogous network visualisation of ion cyclotron resonance Fourier transform (FTICR) mass spectra: Improved options to assign elemental compositions and to classify organic molecular complexity. European Journal of Mass Spectrometry 17:415-421.

Ueda T., Yamashita K., and Kita N. 2006. Chromium Isotopic Study of Ureilite. Meteoritics and Planetary Science Supplement 41, 5178.

Waldner P., and Pelton A. D. 2004. Thermodynamic modeling of the Ni-S system. Zeitschrift für Metallkunde 95:672-681.

Wasson J.T. and Kallemeyn G.W. 1988. Compositions of Chondrites. Philosophical Transactions of the Royal Society of London. Series A, Mathematical and Physical Sciences: 325, No. 1587, The Solar System: Chemistry as a Key to Its Origin, 535544.

Welten K. C., Meier M. M. M., Caffee M. W., Nishiizumi K., Wieler R., Jenniskens P., and Shaddad M. H. 2010. Cosmogenic nuclides in Almahata Sitta ureilites: Cosmic ray exposure age, preatmospheric mass, and bulk density of asteroid 2008 TC3. Meteoritics \& Planetary Science 45:1728-1742.

Weyrauch M. and Bischoff A. 2012. Macrochondrules in chondrites - Formation by melting of mega-sized dust aggregates and/or by rapid collisions at high temperatures? Meteoritics and Planetary Science 47:2237-2250.

Wiechert U., Halliday A., Palme H., and Rumble, D. 2004. Oxygen isotope evidence for rapid mixing of the HED meteorite parent body. Earth and Planetary Science Letters 221 $(1-4): 373-382$.

Wieler R. 2002. Cosmic-ray-produced noble gases produced in meteorites. Rev. Mineral. Geochem. 47:125-170. 
Wilkison S. L. and Robinson M. S. 2000. Bulk density of ordinary chondrite meteorites and implications for asteroidal internal structure. Meteoritics and Planetary Science 35:1203-1213.

Williams N. H. 2015. The origin of titanium isotopic anomalies within solar system material. PHD thesis, The University of Manchester.

Yamakawa A., Yamashita K., Makishima A., and Nakamura E. 2010. Chromium isotope systematics of achondrites: Chronology and isotopic heterogeneity of the inner solar system bodies. The Astrophysical Journal 720 (1), 150:20-24.

Zhang J., Dauphas N., Davis A. M., Leya I. and Fedkin A. 2012. The proto-Earth as a significant source of lunar material. Nature Geoscience 5:251-255.

Zhang J., Dauphas N., Davis A. M. and Pourmand A. 2011. A new method for MC-ICPMS measurement of Ti isotopic composition: identification of correlated isotope anomalies in meteorites. J. Anal. At. Spectrom. 26:2197-2205. 
Table 1: The Stubenberg meteorite finds (GPS coordinates of the locations referring to the WGS84 datum). The polished sections studied in Münster and Jena were prepared from the $1.298 \mathrm{~g}$ piece of M1d and M6, respectively. The bulk chemical studies (Brest) and isotopic studies (Zurich) were performed on samples of M1h.

\begin{tabular}{|c|c|c|c|c|}
\hline No. & Mass (g) & $\begin{array}{l}\text { Date of find } \\
\text { (yyyy/mm/dd) }\end{array}$ & $\begin{array}{l}\text { Latitude }(\mathrm{N}) \\
\text { Longitude }(\mathrm{E})\end{array}$ & $\begin{array}{c}\text { Characteristics of the meteorite piece; } \\
\text { Finder of the specimen }\end{array}$ \\
\hline M1 & 47.88 & 2016/03/12 & $\begin{array}{l}48^{\circ} 17^{\prime} 42.9^{\prime \prime} \\
13^{\circ} 06^{\prime} 58.9^{\prime \prime}\end{array}$ & $\begin{array}{c}\text { Meteorite was scattered into } 17 \text { pieces } \\
\text { at the impact (M1a-M1n); Michael } \\
\text { Krippner: } 6.21 \mathrm{~g}(\mathrm{M} 1 \mathrm{a}) \text {, Sabine } \\
\text { Gumpenberger: } 23.58 \mathrm{~g}(\mathrm{M} 1 \mathrm{~b}) \text {, Mathias } \\
\text { Stricker: } 5.42 \mathrm{~g}(\mathrm{M} 1 \mathrm{e}) \text {, and seven other } \\
\text { finders }\end{array}$ \\
\hline M2 & 7.66 & $2016 / 03 / 23$ & $\begin{array}{l}48^{\circ} 17^{\prime} 44.9^{\prime \prime} \\
13^{\circ} 07^{\prime} 57.7^{\prime \prime}\end{array}$ & $\begin{array}{c}\text { Individual meteorite, broken into two } \\
\text { (fitting) parts of } 7.21 \mathrm{~g}(\mathrm{M} 2 \mathrm{a}) \text { and } 0.45 \mathrm{~g} \\
(\mathrm{M} 2 \mathrm{~b}) \text { at the impact;Ralph Sporn }+ \\
\text { Martin Neuhofer }\end{array}$ \\
\hline M3 & 19.24 & $2016 / 03 / 23$ & $\begin{array}{l}48^{\circ} 17^{\prime} 43.9^{\prime \prime} \\
13^{\circ} 07^{\prime} 45.8^{\prime \prime}\end{array}$ & $\begin{array}{l}\text { Meteorite fragment with primary } \\
\text { and secondary fusion crust; } \\
\text { Ralph Sporn + Martin Neuhofer }\end{array}$ \\
\hline M4 & 42.43 & $2016 / 03 / 26$ & $\begin{array}{l}48^{\circ} 16^{\prime} 58.5^{\prime \prime} \\
13^{\circ} 07^{\prime} 25.0^{\prime \prime}\end{array}$ & $\begin{array}{l}\text { Complete individual meteorite with } \\
\text { signs of flight orientation; Moritz Karl }\end{array}$ \\
\hline M5 & 1320 & 2016/04/01 & $\begin{array}{l}48^{\circ} 18^{\prime} 20.9^{\prime \prime} \\
13^{\circ} 05^{\prime} 36.5^{\prime \prime}\end{array}$ & $\begin{array}{l}\text { Complete, flight oriented individual } \\
\text { meteorite with deep regmaglypts; } \\
\text { Ralph Sporn + Martin Neuhofer }\end{array}$ \\
\hline M6 & 35.89 & 2016/04/03 & $\begin{array}{l}48^{\circ} 17^{\prime} 53.6^{\prime \prime} \\
13^{\circ} 05^{\prime} 59.9^{\prime \prime}\end{array}$ & $\begin{array}{l}\text { Meteorite fragment with fusion crust } \\
\text { and broken faces; Dennis Harries }\end{array}$ \\
\hline Total & 1473 & & $\begin{array}{ll}48^{\circ} & 17.7^{\prime} \\
13^{\circ} & 07.0^{\prime} \\
\end{array}$ & \\
\hline
\end{tabular}


Table 2: Chemical composition of main phases in the Stubenberg fragmental breccia. All data in $\mathrm{wt} \%$ and obtained by electron microprobe. $\mathrm{n} . \mathrm{d}$. = not detected; $\mathrm{n}=$ number of analyses.

\begin{tabular}{|c|c|c|c|c|c|c|c|}
\hline wt\% & Olivine & Pyroxene & Ca-Pyroxene & Plagioclase & Apatite & Merrillite & Chromite \\
\hline & $n=54$ & $n=43$ & $n=6$ & $n=42$ & $n=16$ & $n=4$ & $n=14$ \\
\hline $\mathrm{SiO}_{2}$ & 36.8 & 54.3 & 53.4 & 65.3 & 0.19 & 0.18 & $<0.03$ \\
\hline $\mathrm{TiO}_{2}$ & $<0.02$ & 0.20 & 0.46 & 0.05 & $<0.02$ & $<0.01$ & 3.4 \\
\hline $\mathrm{Al}_{2} \mathrm{O}_{3}$ & $<0.01$ & 0.16 & 0.47 & 20.9 & $<0.01$ & $<0.01$ & 5.2 \\
\hline $\mathrm{Cr}_{2} \mathrm{O}_{3}$ & $<0.02$ & 0.15 & 0.81 & $<0.01$ & $<0.01$ & $<0.01$ & 54.5 \\
\hline $\mathrm{FeO}$ & 27.8 & 16.5 & 6.4 & 0.53 & 0.59 & 0.62 & 32.7 \\
\hline $\mathrm{MnO}$ & 0.47 & 0.46 & 0.22 & $<0.01$ & $<0.02$ & n.d. & 0.64 \\
\hline MgO & 34.0 & 26.4 & 16.0 & $<0.03$ & 0.15 & 3.4 & 1.51 \\
\hline $\mathrm{CaO}$ & $<0.01$ & 1.01 & 21.3 & 2.20 & 52.3 & 46.1 & n.d. \\
\hline $\mathrm{Na}_{2} \mathrm{O}$ & $<0.01$ & $<0.03$ & 0.52 & 9.1 & 0.33 & 2.43 & $<0.01$ \\
\hline $\mathrm{K}_{2} \mathrm{O}$ & $<0.01$ & $<0.01$ & n.d. & 0.92 & $<0.01$ & 0.08 & $<0.01$ \\
\hline $\mathrm{P}_{2} \mathrm{O}_{5}$ & $<0.04$ & $<0.01$ & $<0.01$ & $<0.02$ & 39.6 & 46.4 & $<0.01$ \\
\hline Cl & $<0.01$ & $<0.01$ & n.d. & n.d. & 5.7 & 0.48 & $<0.01$ \\
\hline Total & 99.1 & 99.2 & 99.6 & 99.0 & 98.9 & 99.7 & 98.0 \\
\hline $\mathbf{F a}$ & $31.4 \pm 0.3$ & & & & & & \\
\hline Fs & & $25.4 \pm 0.3$ & $10.3 \pm 0.4$ & & & & \\
\hline Wo & & $2.0 \pm 0.3$ & $43.9 \pm 0.4$ & & & & \\
\hline An & & & & $11.1 \pm 0.4$ & & & \\
\hline Or & & & & $5.5 \pm 1.2$ & & & \\
\hline
\end{tabular}


Table 3: The bulk composition of Stubenberg. Oxides in wt\%, all other elements in ppm.

\begin{tabular}{|c|c|c|c|c|}
\hline wt\% & ICP-AES & ICP-SFMS & ppm & ICP-SFMS \\
\hline $\mathrm{TiO}_{2}$ & 0.13 & 0.12 & $\mathbf{Z r}$ & 5.12 \\
\hline $\mathrm{Al}_{2} \mathrm{O3}$ & 2.17 & & $\mathbf{N b}$ & 0.419 \\
\hline $\mathrm{Fe}_{2} \mathrm{O3}$ & 29.8 & & Cs & 0.0389 \\
\hline MnO & 0.36 & 0.34 & $\mathbf{B a}$ & 3.6 \\
\hline MgO & 24.9 & & $\mathbf{L a}$ & 0.451 \\
\hline $\mathrm{CaO}$ & 1.82 & 1.90 & $\mathrm{Ce}$ & 1.17 \\
\hline $\mathrm{Na}_{2} \mathrm{O}$ & 0.98 & & Pr & 0.175 \\
\hline $\mathbf{K}_{2} \mathbf{O}$ & 0.1 & 0.11 & Nd & 0.858 \\
\hline $\mathrm{P}_{2} \mathrm{O}_{5}$ & 0.31 & 0.30 & Sm & 0.272 \\
\hline ppm & & & $\mathbf{E u}$ & 0.0825 \\
\hline $\mathrm{Cr}$ & 4573 & & Gd & 0.387 \\
\hline $\mathbf{L i}$ & & 2.29 & $\mathbf{T b}$ & 0.0693 \\
\hline $\mathbf{B e}$ & & 0.0287 & Dy & 0.46 \\
\hline $\mathbf{K}$ & & 950 & Ho & 0.101 \\
\hline Sc & 8.7 & 9.33 & $\mathbf{E r}$ & 0.294 \\
\hline $\mathbf{V}$ & 89 & 80.6 & $\mathbf{T m}$ & 0.0437 \\
\hline Mn & & 2606 & $\mathbf{Y b}$ & 0.274 \\
\hline Co & 578 & 536 & $\mathbf{L u}$ & 0.0405 \\
\hline $\mathbf{N i}$ & 12262 & & Hf & 0.144 \\
\hline $\mathbf{C u}$ & & 73.1 & $\mathbf{T a}$ & 0.0193 \\
\hline Zn & & 43.54 & $\mathbf{W}$ & 0.121 \\
\hline $\mathbf{G a}$ & & 5.06 & $\mathbf{P b}$ & 0.102 \\
\hline $\mathbf{R b}$ & & 2.88 & Th & 0.0476 \\
\hline $\mathrm{Sr}$ & 12 & 10.88 & $\mathbf{U}$ & 0.0063 \\
\hline $\mathbf{Y}$ & 2.8 & 2.97 & & \\
\hline
\end{tabular}


Table 4a. Noble gas concentrations and isotope ratios in Stubenberg: $\mathrm{He}, \mathrm{Ne}$, and Ar.

\begin{tabular}{|c|c|c|c|c|c|c|c|c|c|}
\hline & mass / mg & ${ }^{4} \mathrm{He}$ & ${ }^{3} \mathrm{He} /{ }^{4} \mathrm{He}$ & ${ }^{20} \mathrm{Ne}$ & ${ }^{20} \mathrm{Ne} /{ }^{22} \mathrm{Ne}$ & ${ }^{21} \mathrm{Ne} /{ }^{22} \mathrm{Ne}$ & ${ }^{36} \mathrm{Ar}$ & ${ }^{38} \mathrm{Ar} /{ }^{36} \mathrm{Ar}$ & ${ }^{40} \mathrm{Ar} /{ }^{36} \mathrm{Ar}$ \\
\hline & $23.31 \pm 0.01$ & 1184 & & & & & & $1.37 \pm 0.04$ & \\
\hline II & $71.48 \pm 0.01$ & $1201.6 \pm 2.7$ & $602 \pm 5$ & $14.11 \pm 0.10$ & $0.87 \pm 0.04$ & $0.95 \pm 0.04$ & $1.36 \pm 0.05$ & $1.19 \pm 0.06$ & $4060 \pm 160$ \\
\hline
\end{tabular}

Table 4b. Noble gas concentrations and isotope ratios in Stubenberg: $\mathrm{Kr}$ and $\mathrm{Xe}$.

\begin{tabular}{|c|c|c|c|c|c|c|c|c|}
\hline & ${ }^{84} \mathbf{K r}$ & ${ }^{78} \mathrm{Kr} /{ }^{84} \mathrm{Kr}$ & ${ }^{80} \mathrm{Kr} /{ }^{84} \mathrm{Kr}$ & $\begin{array}{l}{ }^{82} \mathrm{Kr} /{ }^{84} \mathrm{Kr} \\
{ }^{84} \mathrm{Kr}=100\end{array}$ & ${ }^{83} \mathrm{Kr} /{ }^{84} \mathrm{Kr}$ & ${ }^{86} \mathrm{Kr} /{ }^{84} \mathrm{Kr}$ & ${ }^{124} \mathrm{Xe} /{ }^{132} \mathrm{Xe}$ & ${ }^{126} \mathrm{Xe} /{ }^{132} \mathrm{Xe}$ \\
\hline I & $0.733 \pm 0.027$ & $1.68 \pm 0.07$ & $15.0 \pm 0.5$ & $27.7 \pm 1.0$ & $28.0 \pm 0.9$ & $28.9 \pm 1.2$ & $0.73 \pm 0.03$ & $0.78 \pm 0.06$ \\
\hline II & $0.668 \pm 0.019$ & $1.88 \pm 0.03$ & $14.71 \pm 0.17$ & $28.1 \pm 0.5$ & $27.6 \pm 0.6$ & $28.8 \pm 0.4$ & $0.705 \pm 0.025$ & $0.821 \pm 0.024$ \\
\hline
\end{tabular}

Table 4c. Noble gas concentrations and isotope ratios in Stubenberg: Xe continued.

\begin{tabular}{|c|c|c|c|c|c|c|c|}
\hline & ${ }^{132} \mathrm{Xe}$ & ${ }^{128} \mathrm{Xe} /{ }^{132} \mathrm{Xe}$ & ${ }^{129} \mathrm{Xe} /{ }^{132} \mathrm{Xe}$ & $\begin{array}{l}{ }^{130} \mathrm{Xe} /{ }^{132} \mathrm{Xe} \\
{ }^{132} \mathrm{Xe}=100\end{array}$ & ${ }^{131} \mathrm{Xe} /{ }^{132} \mathrm{Xe}$ & ${ }^{134} \mathrm{Xe} /{ }^{132} \mathrm{Xe}$ & ${ }^{136} \mathrm{Xe} /{ }^{132} \mathrm{Xe}$ \\
\hline I & $0.95 \pm 0.04$ & $8.9 \pm 0.4$ & $190 \pm 8$ & $15.7 \pm 0.9$ & $80 \pm 4$ & $38.5 \pm 1.8$ & $32.9 \pm 1.5$ \\
\hline II & $0.904 \pm 0.024$ & $9.04 \pm 0.19$ & $195 \pm 3$ & $16.2 \pm 0.3$ & $81.3 \pm 1.5$ & $39.2 \pm 0.7$ & $32.9 \pm 0.6$ \\
\hline
\end{tabular}

Table 4d. Radiogenic, trapped, and cosmogenic noble gas concentrations and production rates used.

\begin{tabular}{|c|c|c|c|c|c|c|c|c|}
\hline${ }^{4} \mathbf{H e r a d}^{\#}$ & ${ }^{40} \mathrm{Ar}_{\mathrm{rad}}{ }^{\#}$ & ${ }^{36} \mathrm{Ar}_{\mathrm{rr}{ }^{\#}}$ & ${ }^{3} \mathbf{H e}_{\cos }{ }^{\#}$ & ${ }^{21} \mathrm{Ne}_{\cos }{ }^{\#}$ & ${ }^{38} \mathbf{A r}_{\cos }{ }^{\#}$ & $\mathbf{P}_{3}^{*}$ & $\mathbf{P}_{21} *$ & $P_{38} *$ \\
\hline I $771 \pm 33$ & $5690 \pm 280$ & $0.18 \pm 0.07$ & $73.2 \pm 0.7$ & $15.8 \pm 0.4$ & $1.966 \pm 0.008$ & 1.957 & 0.4227 & 0.0501 \\
\hline II $793 \pm 33$ & $5530 \pm 310$ & $0.35 \pm 0.06$ & $72.3 \pm 0.6$ & $15.5 \pm 0.3$ & $1.562 \pm 0.007$ & \pm 0.036 & \pm 0.008 & \pm 0.0011 \\
\hline
\end{tabular}

Table 4e. "Shielding indicator" cosmogenic ${ }^{22} \mathrm{Ne} /{ }^{21} \mathrm{Ne}, \mathrm{CRE}$ and nominal gas-retention ages.

\begin{tabular}{llllllll}
\hline & $\left.{ }^{(22} \mathbf{N e}{ }^{2 \mathbf{1}} \mathbf{N e}\right)_{\mathbf{c o s}}$ & $\mathbf{T}_{\mathbf{3}}$ & $\mathbf{T}_{\mathbf{2 1}}$ & $\mathbf{T}_{\mathbf{3 8}}$ & $\mathbf{T}_{\text {average }}$ & $\mathbf{U} / \mathbf{T h}-{ }^{\mathbf{4}} \mathbf{H e}$ & $\mathbf{K}-{ }^{\mathbf{4 0}} \mathbf{A r}$ \\
\hline I & $1.0826 \pm 0.0026$ & $37 \pm 1$ & $37 \pm 1$ & $39 \pm 1$ & $\mathbf{3 6} \pm \mathbf{3}$ & $2.99 \pm 0.10$ & $4.09 \pm 0.08$ \\
II & $1.05 \pm 0.05$ & $37 \pm 1$ & $37 \pm 1$ & $31 \pm 1$ & & $3.06 \pm 0.10$ & $4.05 \pm 0.09$ \\
\hline
\end{tabular}

$\mathrm{He}, \mathrm{Ne}$, Ar concentrations in $10^{-8} \mathrm{~cm}^{3} / \mathrm{g} \mathrm{STP} \mathrm{Kr}$, Xe concentrations given in $10^{-10} \mathrm{~cm}^{3} / \mathrm{g} \mathrm{STP}$. $\mathrm{CRE}$ ages are in Ma, retention ages in Ga. $\mathrm{T}_{\text {average }}$ is the average of all six values including standard deviation. The larger scatter in the ${ }^{38} \mathrm{Ar}$ ages might be due to variations in Ca. Uncertainties do not include systematic uncertainties of the production rate determinations assumed to be typically $15-20 \%$ and uncertainties in the absolute gas calibrations ( $2 \%$ for $\mathrm{He}$, $\mathrm{Ne}, \mathrm{Ar}$ and $5 \%$ for $\mathrm{Kr}$, Xe, Heber et al. 2009).

${ }^{4} \mathrm{He}_{\mathrm{cos}}$ subtracted with $\left({ }^{4} \mathrm{He} /{ }^{3} \mathrm{He}\right)_{\mathrm{cos}}=5.65 \pm 0.45$ (Wieler, 2002), ${ }^{3} \mathrm{He}_{\text {measured }}={ }^{3} \mathrm{He}_{\mathrm{cos}}$ and ${ }^{21} \mathrm{Ne}_{\text {measured }}={ }^{21} \mathrm{Ne}_{\text {cos. }}{ }^{38} \mathrm{Ar}_{\text {cos }}$ is obtained by decomposition of the measured ${ }^{36} \mathrm{Ar} /{ }^{38} \mathrm{Ar}$ into trapped $\left({ }^{36} \mathrm{Ar} /{ }^{38} \mathrm{Ar}=5.32-5.34\right.$, air or Q; Busemann et al., 2000) or cosmogenic $\left({ }^{36} \mathrm{Ar} /{ }^{38} \mathrm{Ar}=\right.$ $0.63-0.67)$. The variations are covered in the uncertainty of ${ }^{38} \mathrm{Ar}_{\cos }$. The measured ${ }^{40} \mathrm{Ar}$ is assumed to be entirely radiogenic. At maximum 0.9 and $1.8 \%$, respectively, of the ${ }^{40} \mathrm{Ar}$ in I and II could be atmospheric, assuming ${ }^{36} \mathrm{Ar}_{\text {tr }}$ to be entirely air.

*Production rates were determined based on the most precise shielding indicator, ${ }^{22} \mathrm{Ne} /{ }^{21} \mathrm{Ne}$ (here measured $=$ cosmogenic), with the data tables given by Leya and Masarik (2009). We used the more precise $\left({ }^{22} \mathrm{Ne} /{ }^{21} \mathrm{Ne}\right)_{\cos }=1.0826 \pm 0.0026$ from Stubenberg I. The found mass of $1470 \mathrm{~g}$ corresponds to a radius of only $4.7 \mathrm{~cm}$, with a density for LL chondrites of $3.29 \mathrm{~g} / \mathrm{cm}^{3}$ (Wilkison and Robinson, 2000). However, the pre-atmospheric mass has been determined to be $600 \mathrm{~kg}$ (Spurný et al., 2016). This limits the maximum radius conservatively to $45 \mathrm{~cm}$ (corresponding to $1200 \mathrm{~kg}$ mass). Based on $\left({ }^{22} \mathrm{Ne} /{ }^{21} \mathrm{Ne}\right)_{\cos }$ and the Leya and Masarik (2009) model, the minimum radius is $35 \mathrm{~cm}$. The production rates and the uncertainties given in the table cover all values allowed in this range. 
Table 5: Massic activities (corrected to the fall of the meteorite March $6^{\text {th }}, 2016$ ) of cosmogenic radionuclides (in dpm $\mathrm{kg}^{-1}$ ) in the specimens M1b and M5 of the Stubenberg stone measured by non-destructive gamma-ray spectroscopy. Errors include a $1 \sigma$ uncertainty of $10 \%$ in the detector efficiency calibration (n.d. = not determined).

\begin{tabular}{|c|c|c|c|}
\hline \multirow[t]{2}{*}{ Nuclide } & \multirow[t]{2}{*}{ Half-life } & \multicolumn{2}{|c|}{ Stubenberg } \\
\hline & & M1b (23.58 g) & M5 (1320 g) \\
\hline$\overline{48} \mathbf{V}$ & $15.9735 \mathrm{~d}$ & $18 \pm 2$ & n.d. \\
\hline${ }^{51} \mathrm{Cr}$ & $27.704 \mathrm{~d}$ & $32 \pm 9$ & n.d. \\
\hline${ }^{7} \mathbf{B e}$ & $53.22 \mathrm{~d}$ & $74 \pm 10$ & $85.4 \pm 8.8$ \\
\hline${ }^{58} \mathrm{Co}$ & $70.83 \mathrm{~d}$ & $4.1 \pm 0.7$ & $4.7 \pm 0.6$ \\
\hline${ }^{56} \mathrm{Co}$ & $77.236 \mathrm{~d}$ & $4.0 \pm 0.7$ & $4.5 \pm 0.6$ \\
\hline${ }^{46} \mathrm{Sc}$ & $83.787 \mathrm{~d}$ & $7.6 \pm 0.8$ & $6.8 \pm 0.7$ \\
\hline${ }^{57} \mathrm{Co}$ & $271.8 \mathrm{~d}$ & $4.9 \pm 0.9$ & $6.0 \pm 1.0$ \\
\hline${ }^{54} \mathrm{Mn}$ & $312.3 \mathrm{~d}$ & $55.1 \pm 5.7$ & $60.9 \pm 4.7$ \\
\hline${ }^{22} \mathbf{N a}$ & $2.60 \mathrm{y}$ & $86.6 \pm 9.0$ & $87.0 \pm 6.7$ \\
\hline${ }^{60} \mathrm{Co}$ & $5.27 \mathrm{y}$ & $0.9 \pm 0.3$ & $<0.5$ \\
\hline${ }^{44} \mathbf{T i}$ & $60 y$ & $<4.8$ & n.d. \\
\hline${ }^{26} \mathrm{Al}$ & $7.17 \times 10^{5} \mathrm{y}$ & $60.7 \pm 4.8$ & $57.4 \pm 4.4$ \\
\hline
\end{tabular}


Table 6: Magnetic susceptibility (MS) of representative individuals and fragments of the Stubenberg fall (compare Table 1) and of LL meteorites (falls only) from the literature for comparison: (1) Rochette et al., 2003, (2) Macke, 2010. N = number of analyzed LLchondrites.

\begin{tabular}{|c|c|c|c|c|}
\hline Sample & Mass [g] or $\mathbf{N}$ & $\begin{array}{c}\text { MS } \\
{\left[10^{-9} \mathrm{~m}^{3} / \mathrm{kg}\right]}\end{array}$ & $\begin{array}{c}\log \mathrm{MS} \\
{\left[10^{-9} \mathrm{~m}^{3} / \mathrm{kg}\right]}\end{array}$ & Ref. \\
\hline M1b & 23.58 & 4868 & 3.687 & this study \\
\hline M1c & 1.834 & 4668 & 3.669 & this study \\
\hline M1n & 2.289 & 4764 & 3.678 & this study \\
\hline M2a & 7.212 & 4889 & 3.689 & this study \\
\hline M3 & 19.236 & 5076 & 3.705 & this study \\
\hline M5 & 1320 & 4723 & 3.674 & this study \\
\hline M6 & 35.887 & 4728 & 3.675 & this study \\
\hline Average & & $4817 \pm 172$ & $3.683 \pm 0.015$ & this study \\
\hline \multirow{2}{*}{ LL 3} & 8 & & $4.37(4.03-4.67)$ & (1) \\
\hline & 5 & & $4.38(4.19-4.57)$ & (2) \\
\hline \multirow{2}{*}{ LL 4} & 5 & & $4.18(3.58-4.43)$ & (1) \\
\hline & 5 & & $4.27(3.61-4.66)$ & (2) \\
\hline \multirow{2}{*}{ LL 5} & 12 & & $4.13(3.70-4.54)$ & (1) \\
\hline & 6 & & $4.21(3.83-4.65)$ & (2) \\
\hline \multirow{2}{*}{ LL 6} & 19 & & $3.95(3.56-4.27)$ & (1) \\
\hline & 16 & & $3.93(3.46-4.71)$ & (2) \\
\hline LL 7 & 1 (Uden) & & 3.33 & (1) \\
\hline
\end{tabular}




\section{Figure Captions:}

Fig. 1: Calculated strewn field near Stubenberg (Germany) with find locations of the six recovered individuals (M1 - M6). The northern part of the strewn field is dominated by forest, in which the samples M5 and M6 were found. Most other areas represent farmland. The river "Inn" marks the border to Austria in the south. Source of base map: Google Earth.

Fig. 2: Images of the six Stubenberg meteorites found between March 12 and April 3, 2016. (a) This broken fragment M1b of $23.58 \mathrm{~g}$ is the largest part of 17 pieces, totaling $47.88 \mathrm{~g}$. (b) A chip of $0.45 \mathrm{~g}$ broke off from the individual meteorite $\mathrm{M} 2 \mathrm{of} 7.66 \mathrm{~g}$ at the impact in a field. (c) The meteorite fragment M3 weighing $19.24 \mathrm{~g}$ was partially buried in the soft ground. (d) Complete individual meteorite M4 of $42.43 \mathrm{~g}$ found on the northern bank of the river Inn. (e) The impact hole of the largest Stubenberg individual meteorite M5 of $1320 \mathrm{~g}$ in the forest ground was $14 \mathrm{~cm}$ deep. (f) The fragment M6 weighing $35.89 \mathrm{~g}$ shows fusion crust on the top, and broken faces at the bottom.

Fig. 3: Photomicrographs of typical features of the Stubenberg fragmental breccia. (a) highlyrecrystallized texture within an LL6 fragment. (b) Fragmented appearance of the bulk rock. The boundaries of individual fragments are well-observable. (c) Large plagioclase grains are common as well as thin shock veins shown in (d). (e) Occasionally, relict chondrules like this BO-chondrule are visible. (f) Olivines show several sets of planar fractures. Abbreviations: plag $=$ plagioclase, $\mathrm{ol}=$ olivine, $\mathrm{py}=$ low-Ca pyroxene, ap $=$ apatite, $\mathrm{m}=$ metal, $\mathrm{tr}=$ troilite, ca-py = Ca-pyroxene. Images in polarized light (a,b,c,f), crossed Nicols (a,c,f); images in back-scattered electrons $(\mathrm{d}, \mathrm{e})$.

Fig. 4: Pentlandite in the Stubenberg meteorite. a) SEM-BSE overview showing the elongated pentlandite-troilite aggregate. b) SEM-BSE detail showing the intergrowth of pentlandite (Pn) and troilite (Tro). Arrows mark the location of an extracted FIB section. c) TEM-SAED pattern of pentlandite close to zone axis [1-10]. d) TEM-SAED pattern of pentlandite and troilite showing the orientation relationship outlined in the text. 
Fig. 5: BSE image of the broken surface of fragment M1h (1.652 g) of the Stubenberg meteorite with troilite (white) and abundant olivine (light grey). The dark grey grains represent plagioclase. Note the well-preserved $120^{\circ}$ triple junctions between the mineral phases.

Fig. 6: Bulk composition of Stubenberg in comparison to the LL chondrite Chelyabinsk. Chelyabinsk data from Righter et al. (2015). For normalization the CI-values of Barrat et al. (2012) are used.

Fig. 7: Neon isotopes show that Stubenberg does not contain implanted solar wind noble gases. Both data points plot exactly on the cosmogenic endmember composition, implying that contributions from trapped $\mathrm{Ne}$ are negligible. For comparison, data for a selection of LL chondrites that contain mostly trapped $\mathrm{Ne}$ (in most cases fractionated solar wind (fSW), are also shown. Typical pure trapped Ne endmembers (air, SW (Heber et al., 2009), and Q (Busemann et al., 2000, 2014) plot in the upper left of the figure). References for LL chondrite literature data: Heymann and Mazor, 1966; Bischoff et al., 1993; Eugster et al., 1993; Scherer et al., 1998; Schultz and Franke, 2004.

Fig. 8: Chromium and oxygen isotopes of Stubenberg in the $\varepsilon^{54} \mathrm{Cr}-\Delta^{17} \mathrm{O}$ isotope diagram compared with other meteorites groups. Different meteorite groups define tight clusters, which imply that they either originate from the same parent bodies or they formed from similar materials. Stubenberg falls within the ordinary chondrite field. Data are from: This study; Trinquier et al. (2008); Qin et al. (2010); Jenniskens et al. (2014); Popova et al. (2013); Yamakawa et al. (2010); Shukolyukov and Lugmair (2006); Ueda et al. (2006); Clayton et al. (1991); Clayton and Mayeda (1984, 1996, 1999); Wiechert et al. (2004); Rumble et al. (2010).

Fig. 9: Negative electrospray ionization mode (ESI) Fourier transform ion cyclotron resonance mass spectrometry ((-) ESI-FT-ICR-MS) FT-ICR-MS analysis of methanolic 
extracts revealed $\sim 600$ elementary compositions in the CHNMgOS space. (A) illustrates the mass profile in the range 150 to $650 \mathrm{amu}$ with a zoomed-in detail on the high chemodiversity, as shown exemplary for the nominal mass 319 . This enlarged mass range shows more than 70 $\mathrm{m} / \mathrm{z}$ signals. Panel (B), (C): The number of nitrogen and sulfur atoms in the molecular compositions is shown as a function of the number of carbon atoms. Addititionally, the soluble organic compositions are depicted in van Krevelen diagram-type representations of the data with additional extension of the CHNOS space (D and E) and the CHOMg space (G). The bubble size represents the relative intensity of the mass peaks and each data point is related to one molecular formula. Panel (F) depicts the distribution of the chemical subspaces CHOMg, CHO, CHOS, CHNO and CHNOS.

Fig. 10: Mid-infrared spectrum of Stubenberg (in black) compared to other LL chondrites Tuxtuac and Paragould (on top) and various Chelyabinsk lithologies (bottom; Morlok et al., 2017). Vertical lines mark characteristic features. Stubenberg does not show the loss of feature strengths exhibited by the Chelyabinsk lithologies resulting from shock metamorphism, thus indicating a generally low degree of impact shock. 


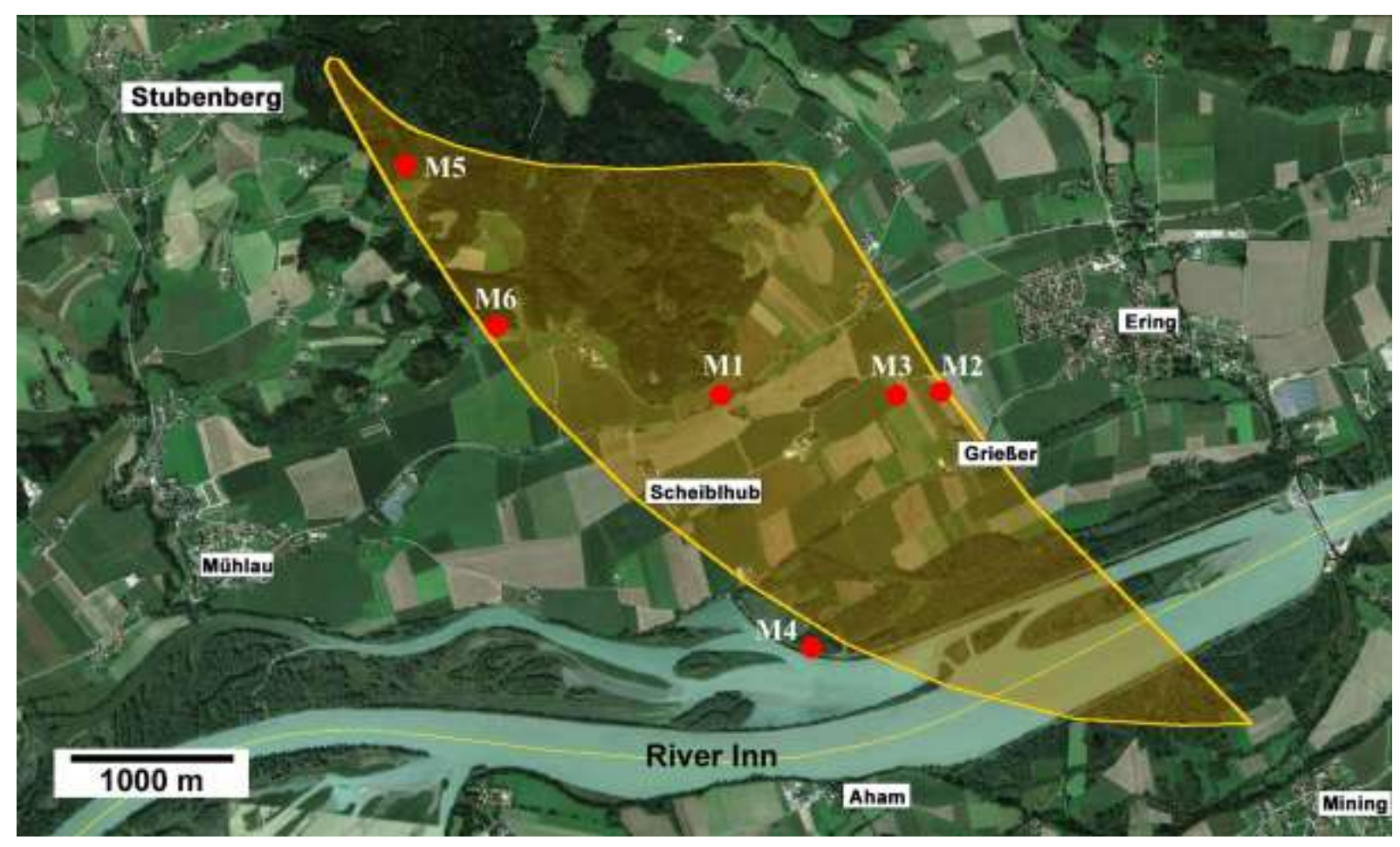

Fig. 1: Calculated strewn field near Stubenberg (Germany) with find locations of the six recovered individuals (M1 - M6). The northern part of the strewn field is dominated by forest, in which the samples M5 and M6 were found. Most other areas represent farmland. The river "Inn" marks the border to Austria in the south. Source of base map: Google Earth 

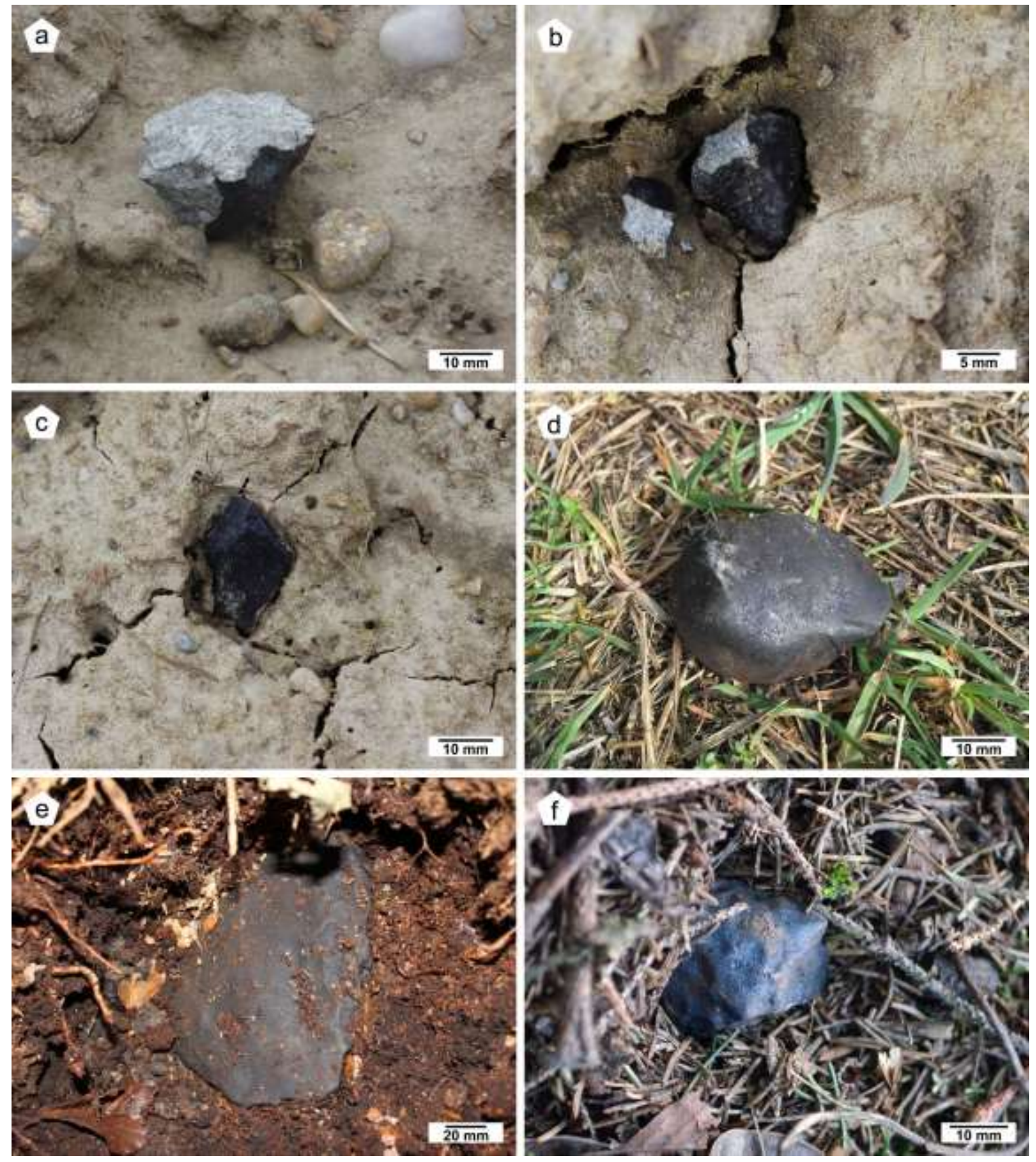

Fig. 2: Images of the six Stubenberg meteorites found between March 12 and April 3, 2016.

(a) This broken fragment M1b of $23.58 \mathrm{~g}$ is the largest part of 17 pieces, totalling $47.88 \mathrm{~g}$. (b) A chip of $0.45 \mathrm{~g}$ broke off from the individual meteorite $\mathrm{M} 2 \mathrm{of} 7.66 \mathrm{~g}$ at the impact in a field. (c) The meteorite fragment M3 weighing $19.24 \mathrm{~g}$ was partially buried in the soft ground. (d) Complete individual meteorite M4 of $42.43 \mathrm{~g}$ found on the northern bank of the river Inn. (e) The impact hole of the largest Stubenberg individual meteorite M5 of $1320 \mathrm{~g}$ in the forest ground was $14 \mathrm{~cm}$ deep. (f) The fragment M6 weighing $35.89 \mathrm{~g}$ shows fusion crust on the top, and broken faces at the bottom. 

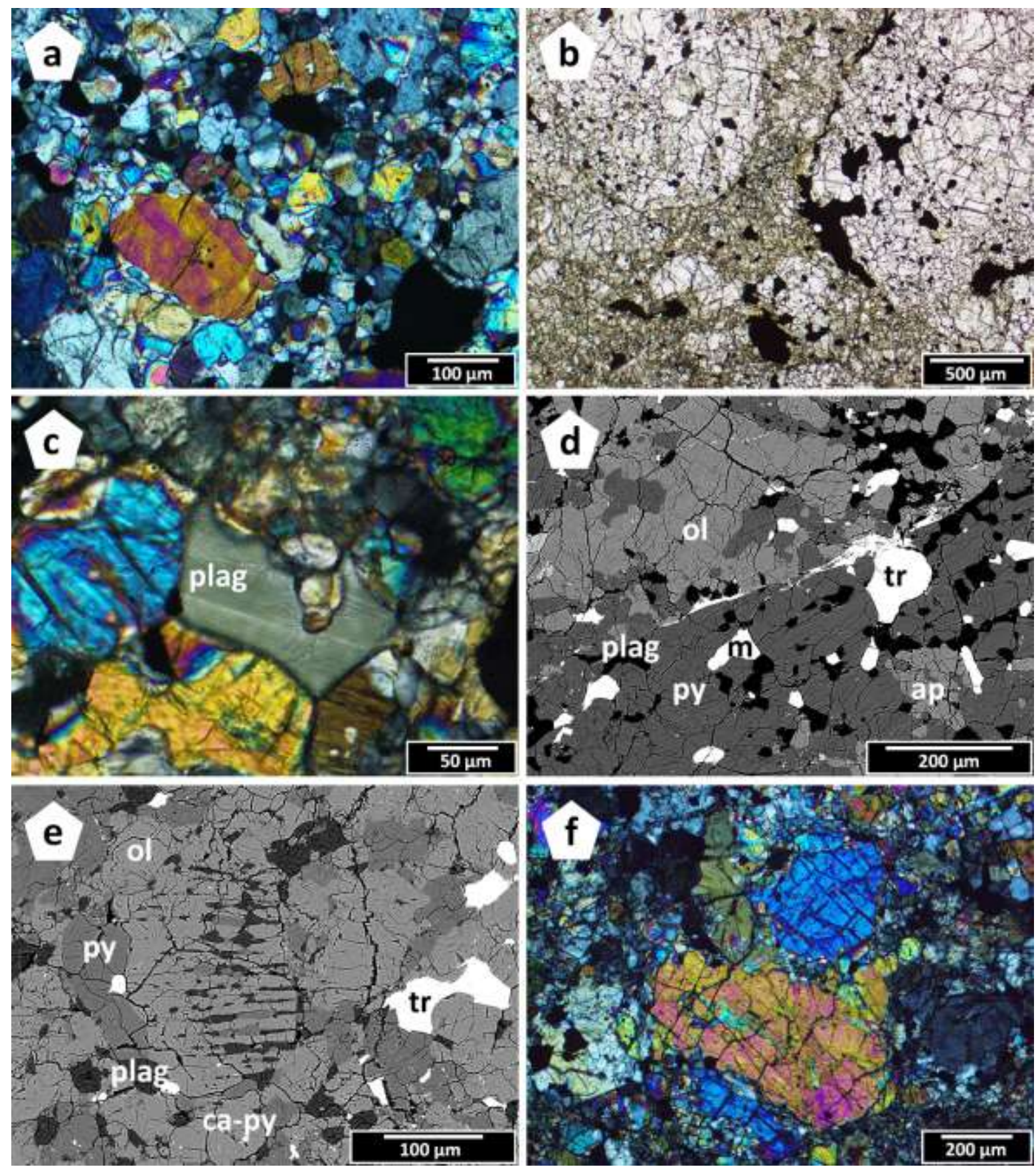

Fig. 3: Photomicrographs of typical features of the Stubenberg fragmental breccia. (a) highlyrecrystallized texture within an LL6 fragment. (b) Fragmented appearance of the bulk rock. The boundaries of individual fragments are well-observable. (c) Large plagioclase grains are common as well as thin shock veins shown in (d). (e) Occasionally, relict chondrules like this BO-chondrule are visible. (f) Olivines show several sets of planar fractures. Abbreviations: plag $=$ plagioclase, $\mathrm{ol}=$ olivine, $\mathrm{py}=$ low-Ca pyroxene, ap $=$ apatite, $\mathrm{m}=$ metal, $\mathrm{tr}=$ troilite, ca-py = Ca-pyroxene. Images in polarized light (a,b,c,f), crossed Nicols (a,c,f); images in back-scattered electrons (d,e). 

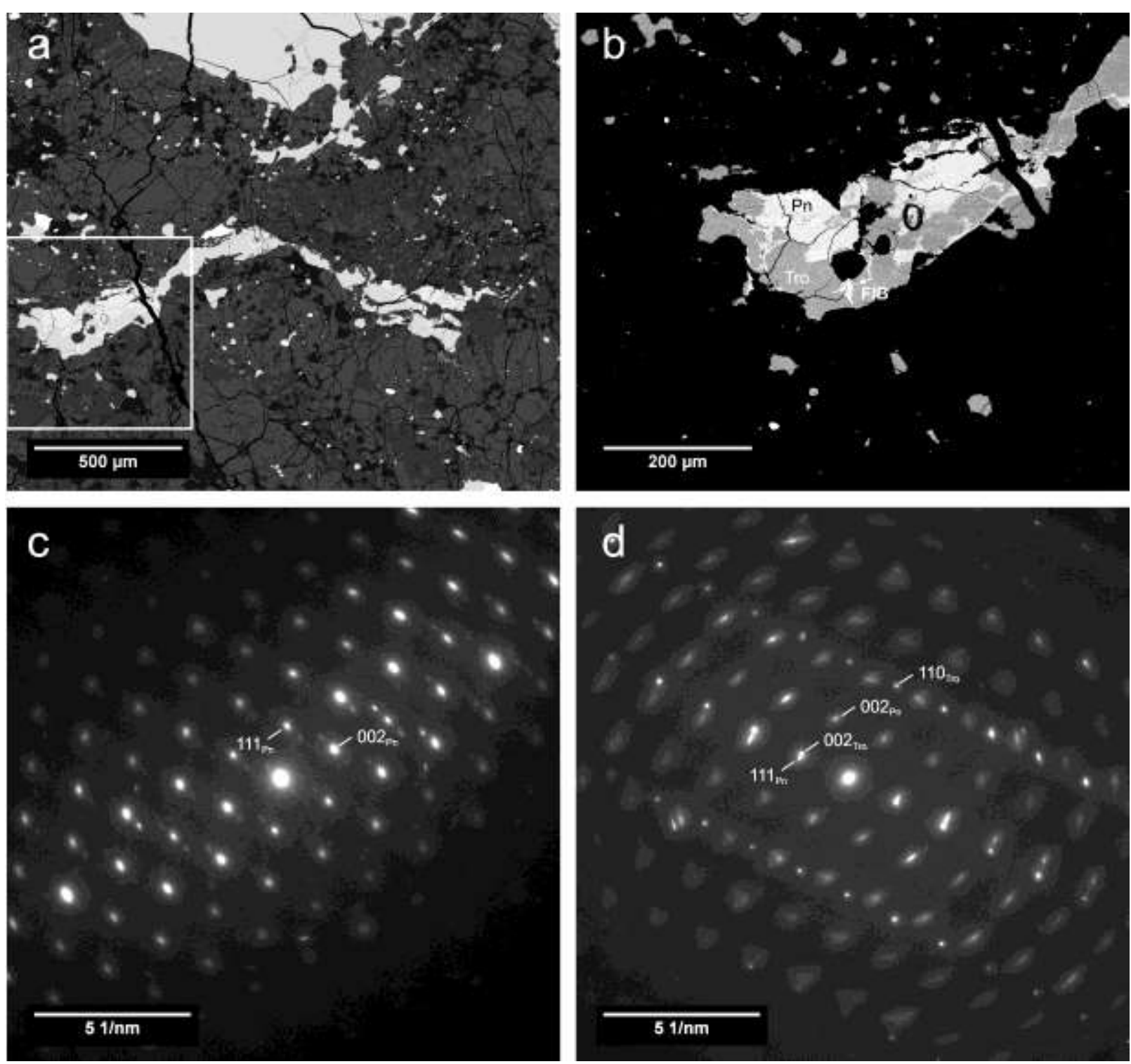

Fig. 4: Pentlandite in the Stubenberg meteorite. a) SEM-BSE overview showing the elongated pentlandite-troilite aggregate. b) SEM-BSE detail showing the intergrowth of pentlandite (Pn) and troilite (Tro). Arrows mark the location of an extracted FIB section. c) TEM-SAED pattern of pentlandite close to zone axis [1-10]. d) TEM-SAED pattern of pentlandite and troilite showing the orientation relationship outlined in the text. 


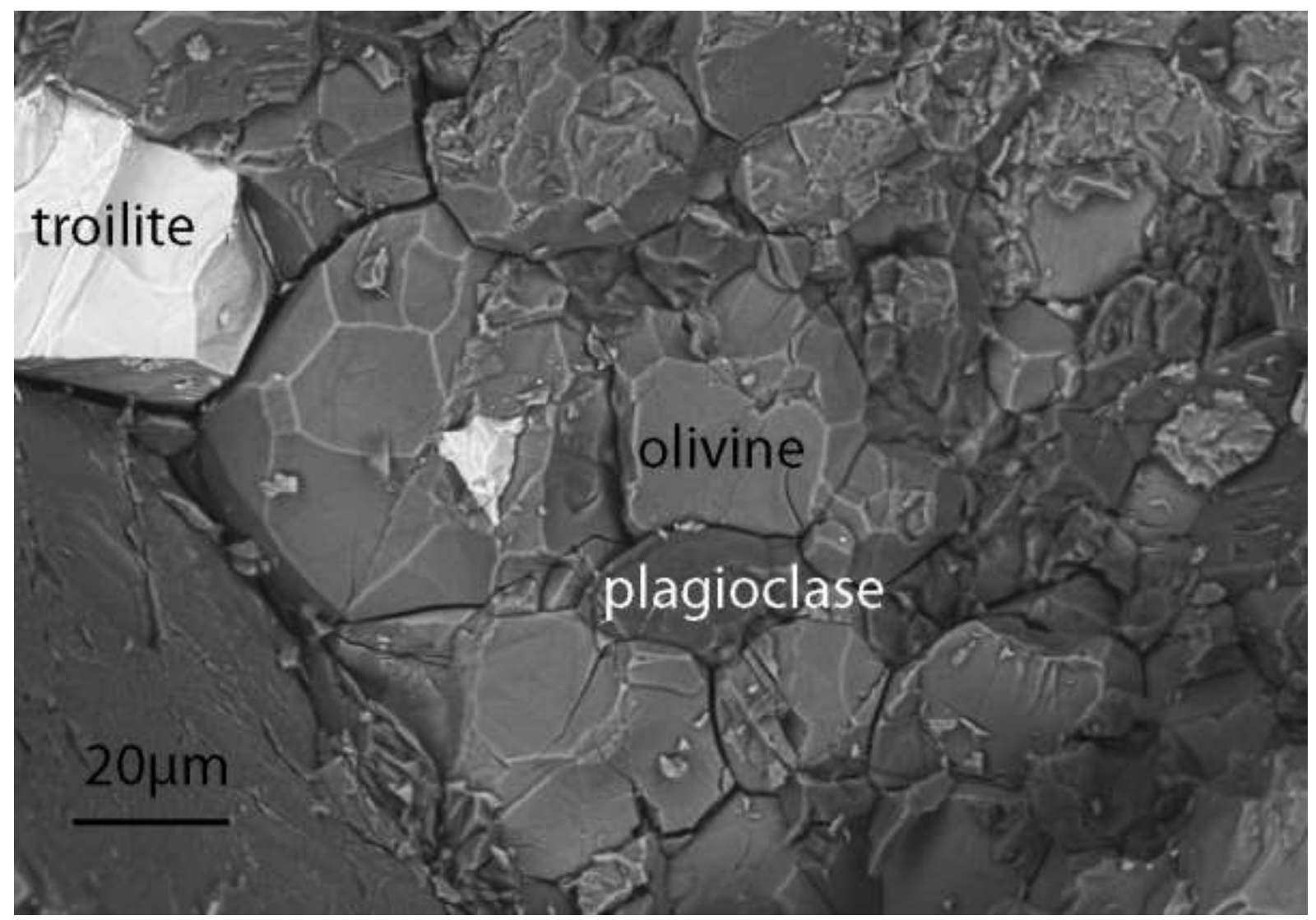

Fig. 5: BSE image of the broken surface of fragment M1h (1.652 g) of the Stubenberg meteorite with troilite (white) and abundant olivine (light grey). The dark grey grains represent plagioclase. Note the well-preserved $120^{\circ}$ triple junctions between the mineral phases. 


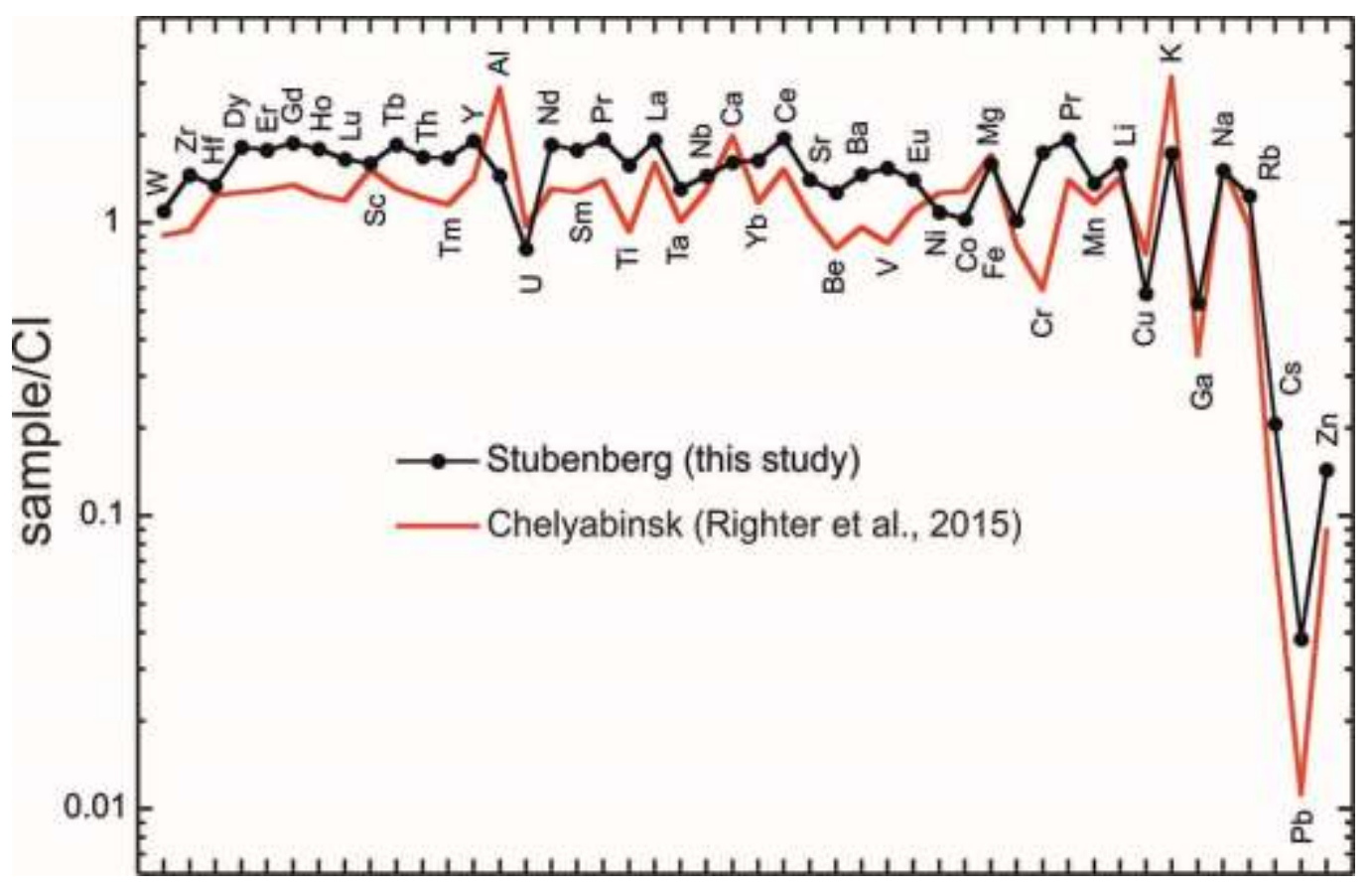

Fig. 6: Bulk composition of Stubenberg in comparison to the LL chondrite Chelyabinsk. Chelyabinsk data from Righter et al. (2015). ). For normalization the CI-values of Barrat et al. (2012) are used. 


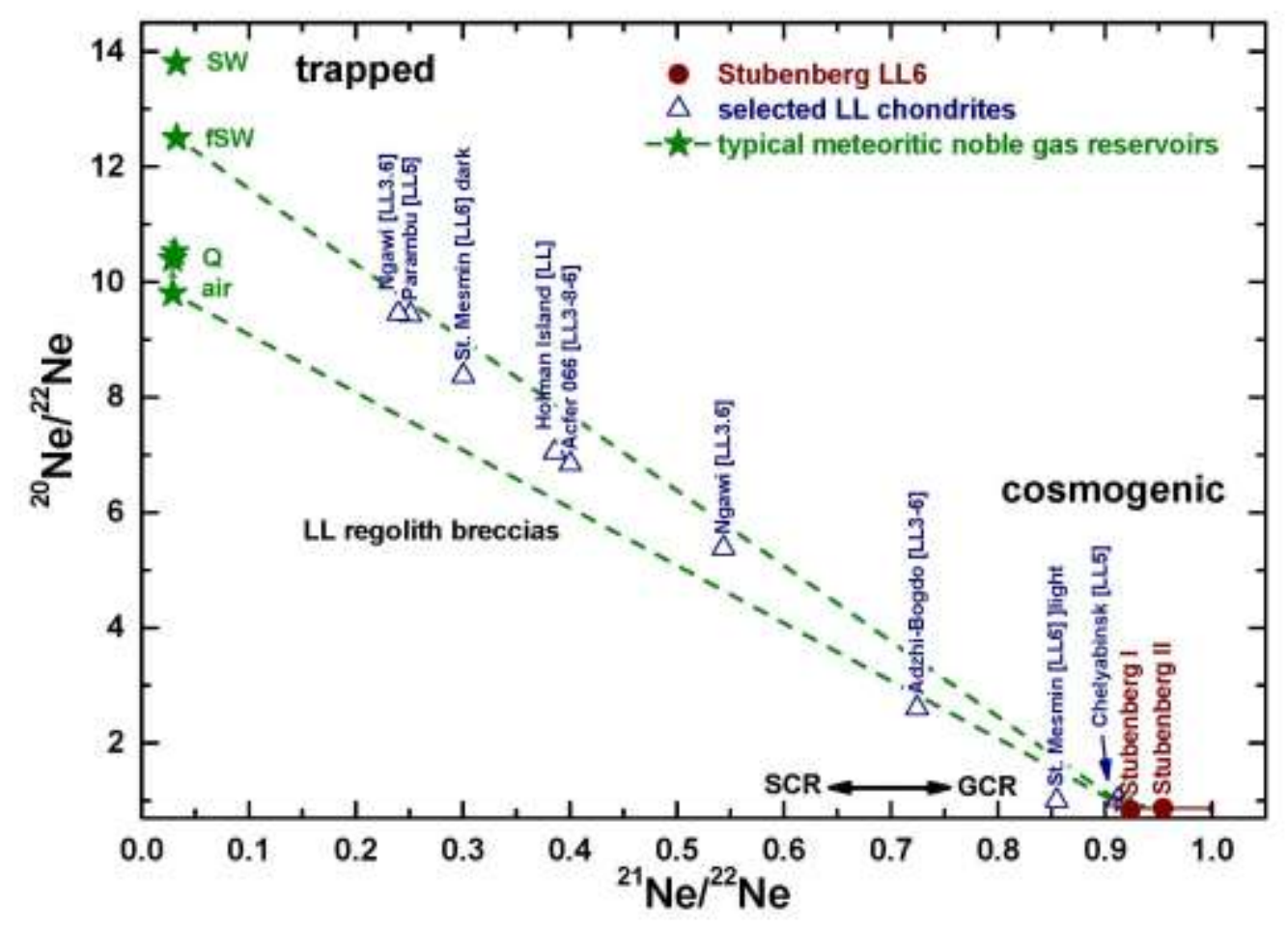

Fig. 7: Neon isotopes show that Stubenberg does not contain implanted solar wind noble gases. Both data points plot exactly on the cosmogenic endmember composition, implying that contributions from trapped $\mathrm{Ne}$ are negligible. For comparison, data for a selection of LL chondrites that contain mostly trapped $\mathrm{Ne}$ (in most cases fractionated solar wind (fSW), are also shown. Typical pure trapped Ne endmembers (air, SW (Heber et al., 2009), and Q (Busemann et al., 2000, 2014) plot in the upper left of the figure). References for LL chondrite literature data: Heymann and Mazor, 1966; Bischoff et al., 1993; Eugster et al., 1993; Scherer et al., 1998; Schultz and Franke, 2004. 


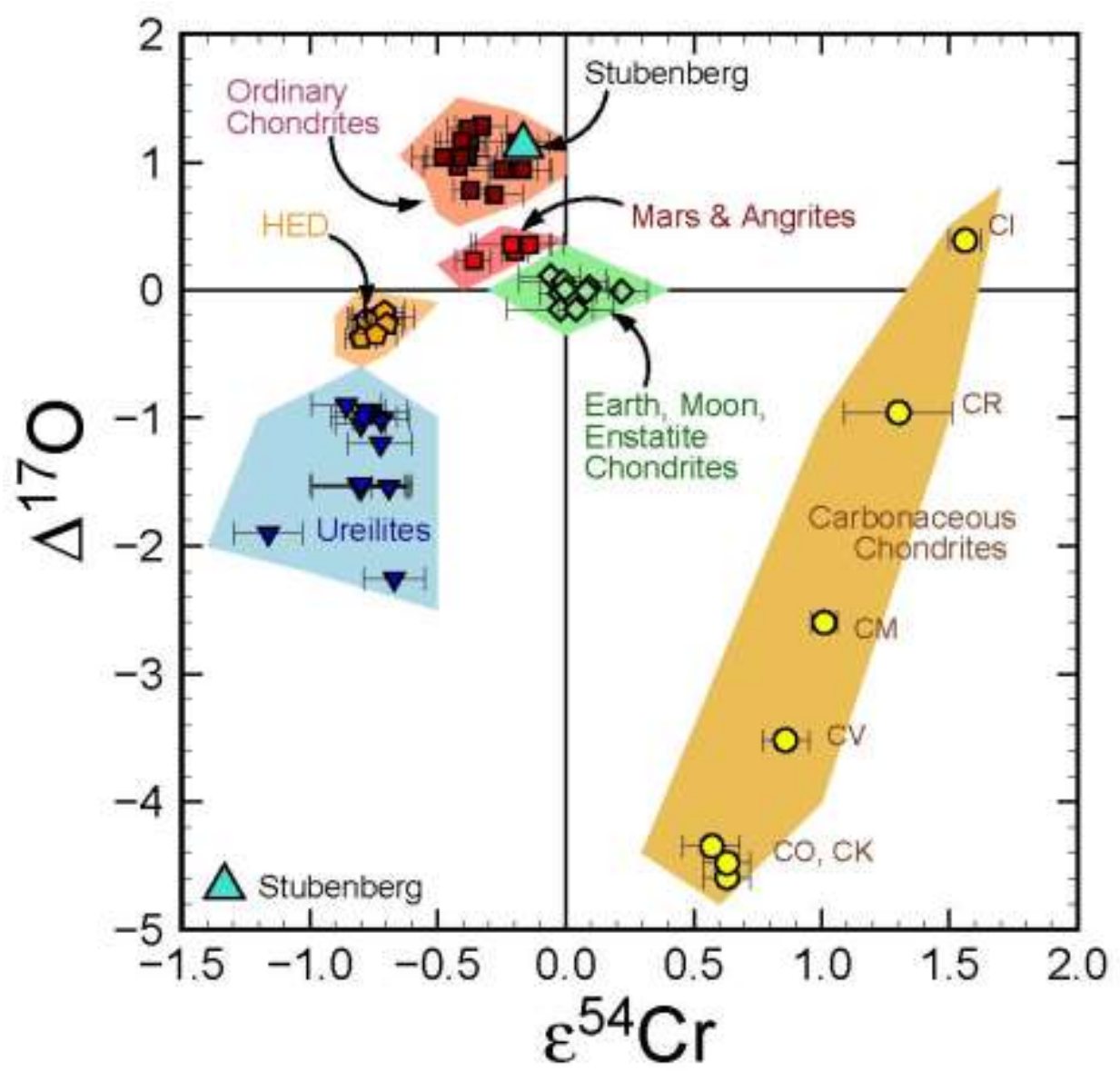

Fig. 8: Chromium and oxygen isotopes of Stubenberg in the $\varepsilon^{54} \mathrm{Cr}-\Delta^{17} \mathrm{O}$ isotope diagram compared with other meteorites groups. Different meteorite groups define tight clusters, which imply that they either originate from the same parent bodies or they formed from similar materials. Stubenberg falls within the ordinary chondrite field. Data are from: this study; Trinquier et al. (2008); Qin et al. (2010); Jenniskens et al. (2014); Popova et al. (2013); Yamakawa et al. (2010); Shukolyukov and Lugmair (2006); Ueda et al. (2006); Clayton et al. (1991); Clayton and Mayeda (1984, 1996, 1999); Wiechert et al. (2004); Rumble et al. (2010). 

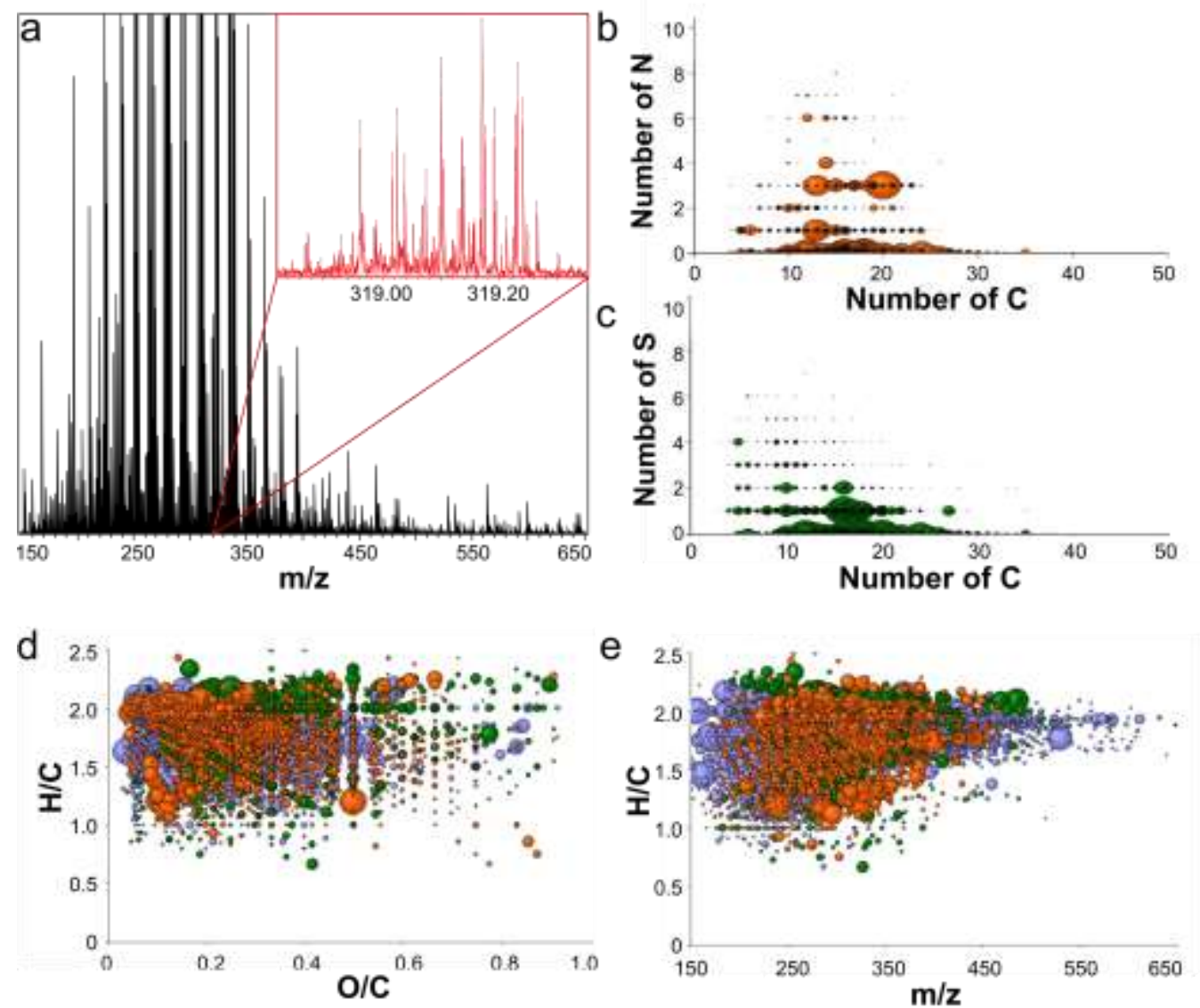

f
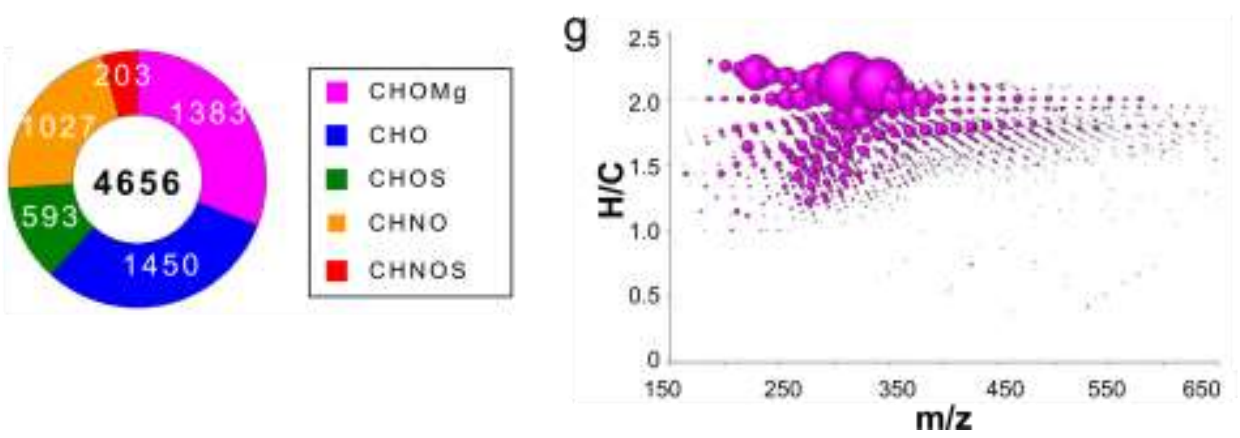

Fig. 9: Negative electrospray ionization mode (ESI) Fourier transform ion cyclotron resonance mass spectrometry ((-) ESI-FT-ICR-MS) FT-ICR-MS analysis of methanolic extracts revealed $\sim 600$ elementary compositions in the CHNMgOS space. (A) illustrates the mass profile in the range 150 to 650 amu with a zoomed-in detail on the high chemodiversity, as shown exemplary for the nominal mass 319 . This enlarged mass range shows more than 70 $\mathrm{m} / \mathrm{z}$ signals. Panel (B), (C): The number of nitrogen and sulfur atoms in the molecular compositions is shown as a function of the number of carbon atoms. Addititionally, the soluble organic compositions are depicted in van Krevelen diagram-type representations of the data with additional extension of the CHNOS space (D and E) and the CHOMg space $(\mathrm{G})$. The bubble size represents the relative intensity of the mass peaks and each data point is related to one molecular formula. Panel (F) depicts the distribution of the chemical subspaces $\mathrm{CHOMg}, \mathrm{CHO}, \mathrm{CHOS}, \mathrm{CHNO}$ and CHNOS. 


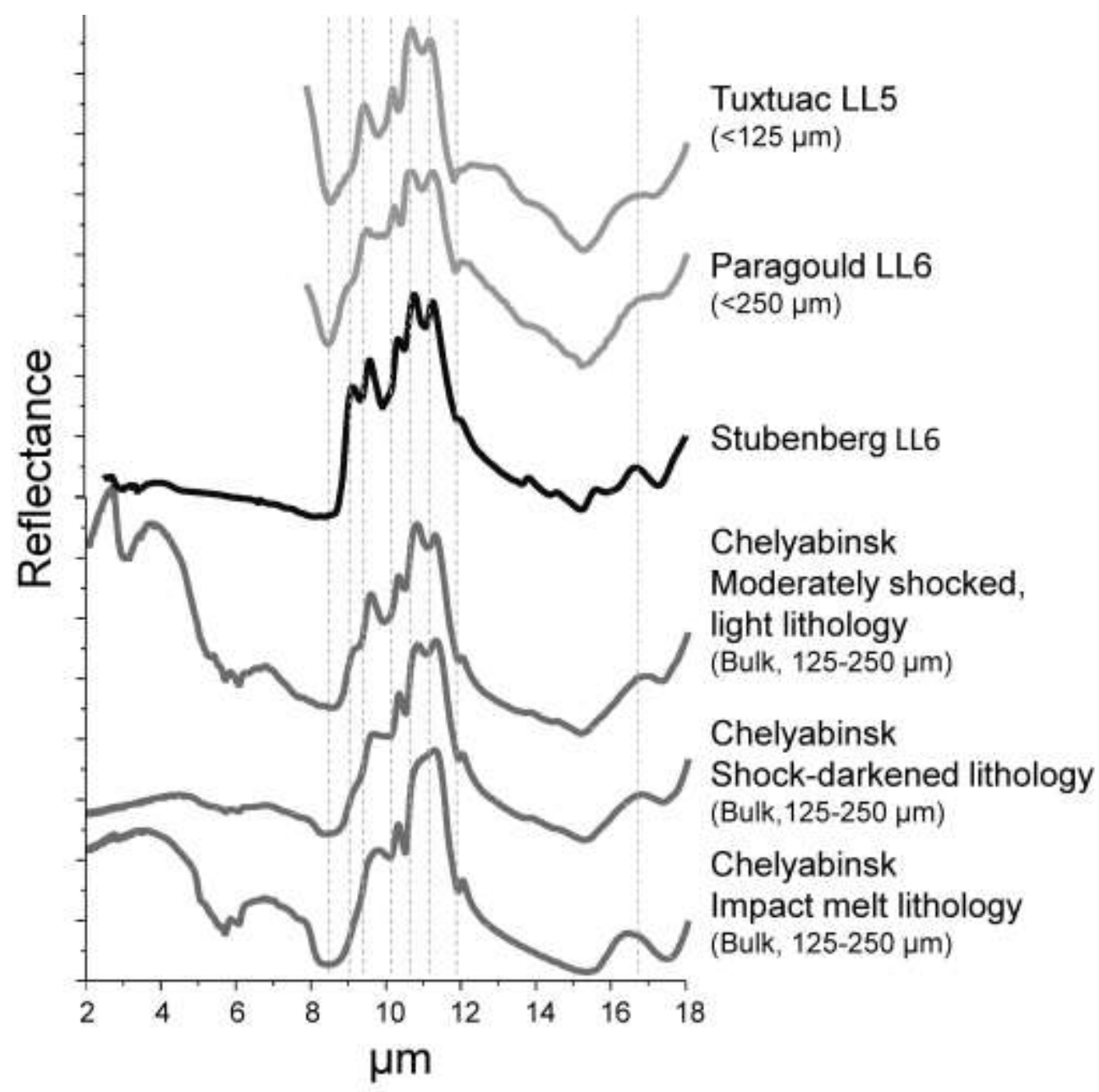

Fig. 10: Mid-infrared spectrum of Stubenberg (in black) compared to other LL chondrites Tuxtuac and Paragould (on top) and various Chelyabinsk lithologies (bottom; Morlok et al., 2017). Vertical lines mark characteristic features. Stubenberg does not show the loss of feature strengths exhibited by the Chelyabinsk lithologies resulting from shock metamorphism, thus indicating a generally low degree of impact shock. 


\section{Supplemental Materials}

\section{Samples and Analytical procedures -}

\section{Optical and electron microscopy}

Several thin and thick sections of Stubenberg (PL16031, PL16032, and PL16033 (thin sections University of Münster); H130,4a (thick section) and H130,4b (thin section) (University of Jena)) were studied by optical and electron microscopy. For optical microscopy in transmitted and reflected light a ZEISS polarizing microscope (Axiophot) was used.

A MIRA3 TESCAN field emission electron microscope at the University of Prague was used to resolve the fine-grained mineral assemblages. In Münster a JEOL 6610-LV electron microscope (SEM) at the Interdisciplinary Center for Electron Microscopy and Microanalysis (ICEM) at the Westfälische Wilhelms-Universität Münster was used to study the fine-grained textures of and to identify the different mineral phases. At the University of Jena a FEI Quanta 3D FEG equipped with an EDAX EDS system was used for mineral characterization and determination of modal abundances via BSE imaging and X-ray elemental mapping. A sulfide sample was extracted for transmission electron microscopy (TEM) using focused ion beam (FIB) preparation (Harries and Langenhorst 2013). The FIB sample was studied using a $200 \mathrm{keV}$ FEI Technai G2 equipped with an Oxford SDD EDS detector. In Munich SEM investigations were conducted with a Zeiss EVO MA10 environmental scanning electron microscope, using a high voltage of $15 \mathrm{kV}$. EDX measurements were performed with an Energy Dispersive X-ray Spectrometer Bruker AXS XFlash 410/M. Fragment M1h (1.652 g) was investigated without any contacting, coating, or sputtering.

\section{Mineral analyses}

Most quantitative mineral analyses were obtained using a JEOL JXA 8900 Superprobe electron microprobe (EPMA) at the ICEM, which was operated at $15 \mathrm{kV}$ and a probe current of $15 \mathrm{nA}$. Natural and synthetic standards were used for wavelength dispersive spectrometry. Jadeite (Na), kyanite (Al), sanidine (K), chromium oxide (Cr), San Carlos olivine (Mg), hypersthene $(\mathrm{Si})$, diopside $(\mathrm{Ca})$, rhodonite $(\mathrm{Mn})$, rutile $(\mathrm{Ti})$, fayalite $(\mathrm{Fe})$, apatite $(\mathrm{P})$, celestine (S), and nickel oxide (Ni) were used as standards for mineral analyses. Penlandite was analyzed at the University of Jena using a JEOL JXA 8230 Superprobe operated at $20 \mathrm{kV}$ and $15 \mathrm{nA}$. Standards used were pyrrhotite ( $\mathrm{S}, \mathrm{Fe})$ and pure metals $(\mathrm{Ni}, \mathrm{Co})$. 
Using the Münster-SEM for quantitative analysis, samples and appropriate mineral standards were measured at an excitation voltage of $20 \mathrm{kV}$, and the beam current constancy was controlled by a Faraday cup. The attached EDS system was used for chemical characterization and analyses of the different mineral constituents. Standard (Astimex) olivine ( $\mathrm{Mg}, \mathrm{Fe}, \mathrm{Si}$ ), jadeite $(\mathrm{Na})$, plagioclase $(\mathrm{Al})$, sanidine $(\mathrm{K})$, diopside $(\mathrm{Ca})$, rutile $(\mathrm{Ti})$, chromium-oxide $(\mathrm{Cr})$, rhodonite $(\mathrm{Mn})$, and pentlandite $(\mathrm{Ni})$ were used as natural and synthetic standards. For these EDS analyses the INCA analytical program provided by Oxford Instruments was used.

\section{Raman Spectroscopy}

Raman spectroscopic investigations were conducted on the following fragments: M1c (1.834 g), M1e (5.418 g), M1h (pieces of $1.652 \mathrm{~g}$ fragment), M1m (0.418 g) and M2b (0.45 g). A Horiba Xplora Integrated confocal Laser micro Raman system on an Olympus BX51 microscope was used for our investigations. Magnifications were between 100 and 1000x (Long Distance objectives 10x and 100x) with acquisition times of 3-5 $\mathrm{s}$ and accumulation numbers of 2-5. The software used was LabSpec 5.78.24 provided by Horiba. The Raman experiments have been performed exclusively on non-prepared samples because in this way we can guarantee to investigate only pristine material excluding any effects of sample preparation/polishing or sputtering (coating).

High resolution mapping was performed in order to detect and identify all potentially present phases and also exsolution/zonation-effects. Point measurements were conducted on phases of special interest. Most Raman spectra have been obtained using a 532nm Nd/YAG Solid State Laser, in a few cases also the $685 \mathrm{~nm}$ Laser was used (for example to suppress higher fluorescence background). Laser power on the sample surface was 8-10 $\mathrm{mW}$, grating was set to 1800 . Optical resolution (Laser spot size) was $0.7 \mu \mathrm{m}$, the Raman spectra precision was $+/-$ $1-2 \mathrm{~cm}^{-1}$.

The following mapping settings have been used: $3 \times 3$ up to $10 \times 10$ maps, point distances of $1 \mu \mathrm{m}$ (individual point spectra overlap reaching higher precision). Measurements were conducted from $50-2500 \mathrm{~cm}^{-1}$, in some cases from $50-4000 \mathrm{~cm}^{-1}$. Baseline correction was performed using degree 6 or 8 polynomials. Peak search and fitting was done with LabSpec "Peak Search" program. Calibration was done manually using Si calibration standards; additional calibration tests were performed using other mineral standards (e.g., olivines from San Carlos, Iceland calcite or standard graphite). 


\section{Bulk chemical analysis}

The sample of about $0.5 \mathrm{~g}$ from Stubenberg fragment M1h was crushed and homogenized. This homogenized sample was used for bulk chemical and isotopic studies in Plouzané, Zurich, and Münster. The chemical composition of the bulk sample was obtained by using ICP-AES and ICP-SFMS. The bulk composition using ICP was performed at the Institut Universitaire Européen de la Mer, Université de Bretagne Occidentale in Plouzané, France.

\section{Ti isotope analyses}

Titanium isotope compositions were measured using Thermo Fisher Scientific Neptune Plus MC-ICPMS at the Institut für Planetologie in Münster and the Institute of Geochemistry and Petrology at ETH Zurich.

For Zurich: A $50 \mathrm{mg}$ sample aliquot in powder form was dissolved in a $6 \mathrm{ml}$ square body Savillex Teflon beakers using $\mathrm{HF}: \mathrm{HNO}_{3}$ (ratio 3:1) in an oven at $160{ }^{\circ} \mathrm{C}$ for 3-4 days (after Prytulak et al., 2011). A three-stage ion exchange procedure for Ti purification was adapted from Williams (2015) with a modification based on Zhang et al. (2011). For the first column, the procedure of Zhang et al. (2011) using TODGA resin was used. This was followed by two repeats of an anion exchange column (Bio-Rad AG1-X8) using 4 M HF for sample loading and matrix elution followed by the elution with $0.5 \mathrm{M} \mathrm{HCl}+0.5 \mathrm{M} \mathrm{HF}$ and the collection of Ti in $6 \mathrm{M} \mathrm{HCl}+1 \mathrm{M} \mathrm{HF}$ (Schönbächler et al., 2004; Williams, 2015). The Ti isotope analyses were performed using a Neptune Plus MC-ICPMS at ETH in high and medium resolving power mode in conjunction with a Cetac Aridus II desolvating system. The samples were bracketed by an in-house $\mathrm{Ti}$ wire standard solution (Williams, 2015). Each sample measurement included one block with 40 integrations of 8.39 seconds for the main and 4.19 seconds for the second line, which is necessary to correct for isobaric interferences. On-peak background corrections were applied and the data was internally normalized to ${ }^{49} \mathrm{Ti} /{ }^{47} \mathrm{Ti}$ $=0.749766$ (Niederer et al., 1981). The sample uncertainty is reported as standard error based on repeated analyzes of the sample solution obtained on three different days.

For Münster: About $50 \mathrm{mg}$ of the sample powders were dissolved in $15 \mathrm{ml}$ Savillex Teflon beakers on a hotplate at $170{ }^{\circ} \mathrm{C}$ for several days with a mixture of $\mathrm{HF}: \mathrm{HNO}_{3}$ (ratio 3:1) and aqua regia, and Ti was separated from the matrix broadly following previously established procedures (Zhang et al., 2011). Titanium isotope measurements were made using Thermo Scientific Neptune Plus MC-ICPMS in high resolving power mode (Zhang et al., 2011). 
Solutions containing about 200 ppb Ti were introduced through a Cetac Aridus II desolvating system, resulting in a $\sim 4 \times 10^{-10} \mathrm{~A}$ ion beam on ${ }^{48} \mathrm{Ti}$. Measurements consisted of a $30 \mathrm{~s}$ baseline measurement (deflected beam) followed by 20 isotope ratio measurements of $8 \mathrm{~s}$ each. Mass bias was corrected using the exponential law and ${ }^{49} \mathrm{Ti} /{ }^{47} \mathrm{Ti}=0.749766$. Titanium isotope anomalies are reported as parts per ten thousand deviation ( $\varepsilon$-notation) from the terrestrial OL-Ti (Millet and Dauphas, 2014) bracketing standard. The sample uncertainty is reported as standard error (student-t $95 \%$ confidence interval) based on repeated analyzes of the sample solution obtained on three different days.

\section{Cr isotope analyses}

Chromium isotope compositions were determined by MC-ICPMS at the Institute of Geochemistry and Petrology at ETH Zurich and are described in more detail in Steele and Schönbächler (2016). An aliquot of the same dissolution analyzed for Ti isotopes in Zurich, was also analyzed for $\mathrm{Cr}$ isotope composition. It was verified that the dissolution method of Prytulak et al. (2011) dissolves refractory phases such as spinel and chromites, which contain significant amounts of $\mathrm{Cr}$ and are not readily dissolved during hotplate dissolution. Chromium was separated from the sample matrix using a three stage ion exchange procedure. A first column, developed from Trinquier et al. (2008), used AG-50W cationic resin and $1 \mathrm{M} \mathrm{HCl}$ to isolate $\mathrm{Cr}$ from the bulk of the matrix. Two subsequent columns adapted from Steele et al. (2011) were used to separate $\mathrm{Cr}$ from direct isobaric interferences (Tru.Spec, Ti, V, and Fe), residual matrix and organic species (AG-50W). Chromium isotope compositions were determined using a Neptune Plus MC-ICPMS in high-resolving power mode $(\mathrm{M} / \Delta \mathrm{M}>9000)$ to resolve isobaric interferences from the plasma gasses ( $\mathrm{ArC}, \mathrm{ArN}$, and $\mathrm{ArO})$. Samples were introduced as $6 \mathrm{ppm}$ solutions in $0.4 \mathrm{M} \mathrm{HNO}_{3}$ using a Cetac Aridus II desolvating nebuliser and yielded a $\sim 1.5 \mathrm{nA}{ }^{52} \mathrm{Cr}$ ion beam. Each sample measurement was bracketed by an on peak blank measurement, which was subtracted, and a Cr NIST SRM 979 standard measurement (also blank corrected). A sample or standard measurement consisted of 80 cycles of $16 \mathrm{~s}$ integrations and blank measurements were 40 cycles of $8 \mathrm{~s}$ integrations. Samples and standards were corrected for natural and instrumental mass-dependent isotope fractionation using the exponential law (Russell et al., 1978) and ${ }^{50} \mathrm{Cr} /{ }^{52} \mathrm{Cr}=0.051859$ (Shields et al., 1966). The isotope composition is reported as the parts per ten thousands deviation from the Cr NIST SRM 979 standard. The sample was measured 3 times and the isotope composition and uncertainty are the average and standard error of these repeat measurements. The 
uncertainty was corrected for small sample bias using the method of Gurland and Tripathy (1971) and is in agreement with the long-term external precision.

\section{Noble gas studies}

The noble gases He-Xe in two bulk samples "I" (23.3 mg) and "II" (71.5 mg) were analyzed at ETH Zurich. We extracted the gases in one temperature step at $\sim 1700{ }^{\circ} \mathrm{C}$, with the standard procedures described in detail by Riebe et al. (2017, in revision). Blank corrections were mostly negligible ( $<0.3 \%$ for all $\mathrm{He}, \mathrm{Ne}$, and Ar isotopes), but 7 and $19 \%$ for ${ }^{84} \mathrm{Kr}$, and 3 and $8 \%$ for ${ }^{132} \mathrm{Xe}$ for the smaller (I) and larger (II) sample, respectively. A re-extraction step at slightly elevated temperature $\left(1750{ }^{\circ} \mathrm{C}\right)$ showed that sample I was completely degassed in the main step. Concentrations and isotope ratios are given in the Appendix of Table 4.

\section{Radionuclides}

Cosmogenic radionuclide concentrations have been analyzed by means of non-destructive high purity germanium (HPGe) gamma spectroscopy. The counting efficiencies have been calculated using thoroughly tested Monte Carlo codes. The specimen M1b (23.58 g) was measured in the underground laboratories at the Laboratori Nazionali del Gran Sasso (LNGS) (Arpesella, 1996), whereas piece M5 (1320 g) was measured at the low level laboratory of the Max-Planck Institut für Kernphysik (Heusser et al., 2015). The specimen M1b was received at LNGS already 14 days after the fall, so that also rather short-lived radionuclides such as ${ }^{48} \mathrm{~V}$, and ${ }^{51} \mathrm{Cr}$ could be measured.

\section{Oxygen isotope analyses}

The oxygen isotope composition of Stubenberg was analyzed by means of laser fluorination in combination with gas source mass spectrometry (Sharp, 1990). The sample was loaded along with San Carlos olivine in a 19-pit stainless steel sample holder. We used a 2-window (quartz glass viewing port and $\mathrm{BaF}_{2}$ for the $\mathrm{CO}_{2}$ laser beam) sample chamber as described in Sharp (1990). The samples were fluorinated with $\sim 40$ mbar $\mathrm{BrF}_{5}$. The unwanted gaseous reaction products (mainly $\mathrm{BrF}_{5-\mathrm{x}}$ and $\mathrm{SiF}_{4}$ ) were removed my means of cryogenic trapping. The sample $\mathrm{O}_{2}$ was collected at $-196{ }^{\circ} \mathrm{C}$ on $5 \AA$ molecular sieve for $7 \mathrm{~min}$. For further purification (removal of $\mathrm{N}_{2}$ and $\mathrm{NF}_{3}$ ), sample $\mathrm{O}_{2}$ was transported with a $\mathrm{He}$ carrier gas stream through a $3 \mathrm{~m}$ long packed molecular sieve gas chromatography column (Restek) that was kept at $50{ }^{\circ} \mathrm{C}$. The sample $\mathrm{O}_{2}$ was then collected downstream in a second, low volume 
molecular sieve trap. After evacuation of He from the second trap, sample $\mathrm{O}_{2}$ was expanded to the bellows of a Thermo MAT253 gas source mass spectrometer. The sample gas was analyzed relative to a working gas for $\sim 60$ minutes (90 cycles). The external reproducibility of San Carlos olivine measurements was $0.1 \%$ for $\delta^{18} \mathrm{O}$ and $0.006 \%$ for $\Delta^{, 17} \mathrm{O}(1 \sigma \mathrm{SD}$, single analysis). The data were normalized to the composition of San Carlos olivine $\left(\delta^{17} \mathrm{O}_{\text {vsmow } 2}=2.715, \delta^{18} \mathrm{O}_{\text {vsmow2 }}=5.220 \%\right.$; see Pack et al., 2016 $)$.

\section{FTIR Spectroscopy}

Measurements were made using a Bruker Vertex 70v at the IR/IS laboratory of the Institut für Planetologie in Münster. We analyzed polished thin sections and rough, unprepared surfaces of meteorite sample. All analyses were collected using identical incidence and emergence angles $\left(30^{\circ} / 30^{\circ}\right)$, using a Bruker A513 bidirectional reflectance stage. For each individual spectrum, 512 scans were accumulated in the wavelength range from 2 to $18 \mu \mathrm{m}$. All reflectance analyses were made at low pressure $\left(10^{-3}\right.$ bar). For background calibration, either a polished gold mirror (for thin section analyses) or a diffuse reflectance standard (rough surfaces) was used. The spectra will be made available as part of the Berlin Emission Database (BED), a mid-infrared spectral database to provide data for the MERTIS (MErcury Radiometer and Thermal Infra-red Spectrometer) mid-infrared spectrometer on the upcoming ESA/JAXS BepiColombo mission to Mercury and later missions (Benkhoff et al., 2010; Hiesinger et al., 2010).

\section{Organics}

A destructive methanolic solvent extraction of organics matter was performed in a pillar using $50 \mathrm{mg}$ freshly broken fragment of the Stubenberg meteorite (from sample M1j). All precautions were taken to avoid external organic contamination and the broken parts were washed intensively with the solvent prior crashing. Negative electrospray ionization mode (ESI) Fourier transform ion cyclotron resonance mass spectrometry (FT-ICR-MS) was undertaken using standard operation procedure as described previously by Schmitt-Kopplin et al. (2010, 2012) and 3,000 scans were averaged. The polar, protic solvent extraction (methanol) and mild ESI-ionization preferentially extracted and ionized polar, oxygenized molecules. Data processing was carried out using the Compass Data Analysis 4.0 (Bruker, Bremen, Germany) and molecular formulas were assigned by a custom made software (NetCalc network), as described by Tziotis et al. (2011). Assigned molecular formulas were 
classified into $\mathrm{CHO}$, CHNO, CHOS, CHNOS, and CHOMg molecular series, which were visualized in the class-selective van Krevelen diagrams (Schmitt-Kopplin et al., 2010, 2012; Hertkorn et al., 2015; Ruf et al., 2017).

\section{Physical Properties}

Magnetic susceptibility (MS) was determined for seven meteorites and fragments of the Stubenberg fall. Dependent on size and geometry up to five measurements per sample were performed with the SM30 of ZH Instruments.

\section{References-Supplement:}

Arpesella C., 1996. A low background counting facility at Laboratori Nazionali del Gran Sasso. Appl. Radiation Isotopes 47:991-996.

Benkhoff J., van Casteren J., Hayakawa H. Fujimoto M., Laakso H., Novara M., Ferri P., Middleton H. R., and Ziethe R. 2010. BepiColombo---Comprehensive exploration of Mercury: Mission overview and science goals. Planetary and Space Science 58:2-20.

Gurland J., and Tripathi R. C. 1971. A simple approximation for unbiased estimation of the standard deviation. The American Statistician 25:30-32.

Harries D., and Langenhorst F. 2013. The nanoscale mineralogy of Fe,Ni sulfides in pristine and metamorphosed CM and CM/CI-like chondrites: Tapping a petrogenetic record. Meteoritics and Planetary Science 48:879-903.

Hertkorn N., Harir M., and Schmitt-Kopplin Ph. 2015. Nontarget analysis of Murchison soluble organic matter by high-field NMR spectroscopy and FTICR mass spectrometry. Magnetic Resonance Chemistry, 53:754-768.

Heusser G., Weber M., Hakenmüller J., Laubenstein M., Lindner M., Maneschg W., Simgen H., Stolzenburg D. and Strecker H. 2015. GIOVE: a new detector setup for high sensitivity germanium spectroscopy at shallow depth. The European Physical Journal C 75:531.

Hiesinger H., Helbert J., Mertis and Co-I Team 2010. The Mercury Radiometer and Thermal Infrared Spectrometer (MERTIS) for the BepiColombo mission. Planetary and Space Science 58:144-165.

Millet M.-A, and Dauphas, N. 2014. Ultra-precise titanium stable isotope measurements by double-spike high resolution MC-ICP-MS. J. Anal. At. Spectrom. 29:1444-1458

Niederer F.R., Papanastassiou D.A., and Wasserburg G.J. 1981. The isotopic composition of titanium in the Allende and Leoville meteorites. Geochimica et Cosmochimica Acta 45:1017-1031.

Pack A., Tanaka R., Hering M., Sengupta S., Peters S., and Nakamura E. 2016. The oxygen isotope composition of San Carlos olivine on VSMOW2-SLAP2 scale, Rapid Commun. Mass Spectrom. 30:1495-1504. 
Prytulak J., Nielsen S. G., and Halliday A. N. 2011. Determination of precise and accurate ${ }^{51} \mathrm{~V} /{ }^{50} \mathrm{~V}$ isotope ratios by multi-collector ICP-MS, part 2: Isotopic composition of six reference materials plus the Allende chondrite and verification tests. Geostandards and Geoanalytical Research 35 (3):307-318.

Riebe M. E. I., Welten K., Meier M. M. M., Wieler R., Barth M. I. F., Ward D., Bischoff A., Caffee M. W., Nishiizumi K., and Busemann H. 2017. Cosmic-ray exposure ages of six chondritic Almahata Sitta fragments. Meteoritics \& Planetary Science (in revision).

Ruf A., Kanawati B., Hertkorn N., Yin Q. Z., Moritz F., Harir M., Lucio M., Michalke B., Wimpenny J., Shilobreeva S., Bronsky B., Saraykin V., Gabelica Z., Gougeon R., Quirico E., Ralew S., Jakubowski T., Haack H., Jenniskens P., N.W. Hinman and Schmitt-Kopplin Ph. 2017. Previously unknown class of metalorganic compounds revealed in meteorites, Proceedings of the National Academy of Sciences, doi: 10.1073/pnas.1616019114.

Russell W., Papanastassiou D., and Tombrello T. 1978. Ca isotope fractionation on the Earth and other Solar System materials. Geochimica et Cosmochimica Acta 42:1075-1090.

Schmitt-Kopplin Ph., Gabelica Z., Gougeon R.D., Fekete A., Kanawati B., Harir M., Gebefuegi I., Eckel G., and Hertkorn N. 2010. High molecular diversity of extraterrestrial organic matter in Murchison meteorite revealed 40 years after its fall. PNAS, 107(7):2763-2768.

Schmitt-Kopplin Ph., Harir M., Kanawati B., Tziotis D., Hertkorn N., and Gabelica Z. 2012. Chemical footprint of the solvent soluble extraterrestrial organic matter occluded in Sołtmany ordinary chondrite, Meteorite Journal, Special issue Soltmany, 1-2:79-92.

Schönbächler M., Rehkämper M., Lee D.-C., and Halliday A. N. 2004. Ion exchange chromatography and high precision isotopic measurements of zirconium by MC-ICPMS. Analyst 129:32-37.

Sharp Z. D. 1990. A laser-based microanalytical technique for in situ determination of oxygen isotope ratios of silicates and oxides, Geochim. Cosmochim. Acta 54:1353-1357.

Shields W. R., Murphy T. J., Catanzaro E. J., and Garner E. L. 1966. Absolute isotopic abundance ratios and the atomic weight of a reference sample of chromium. Journal of Research of the National Bureau of Standards A 70:193-197.

Steele R. C. J. and Schönbächler M. 2016. High precision mass-independent Cr isotope compositions by MC-ICPMS and MC-TIMS: application to terrestrial and meteorite samples. Goldschmidt abstract, \#2947.

Steele R. C. J., Elliott T., Coath C. D., and Regelous M. 2011. Confirmation of massindependent $\mathrm{Ni}$ isotopic variability in iron meteorites. Geochimica et Cosmochimica Acta 75:7906-7925.

Trinquier A., Birck J.-L., and Allègre, C. J. 2008. High-precision analysis of chromium isotopes in terrestrial and meteorite samples by thermal ionization mass spectrometry. Journal of Analytical Atomic Spectrometry 23:1565-1574.

Tziotis D., Hertkorn, N., and Schmitt-Kopplin, Ph. 2011. Kendrick-analogous Network Visualisation of Ion Cyclotron Resonance Fourier Transform (FTICR) Mass Spectra: Improved Options to Assign Elemental Compositions and to Classify Organic Molecular Complexity, European Journal of Mass Spectrometry 17:415-421. 
Williams N. H. 2015. The origin of titanium isotopic anomalies within solar system material. PHD thesis, The University of Manchester.

Zhang J., Dauphas N., Davis A. M., and Pourmand A. 2011. A new method for MC-ICPMS measurement of $\mathrm{Ti}$ isotopic composition: identification of correlated isotope anomalies in meteorites. J. Anal. At. Spectrom. 26:2197-2205. 
Supplementary Figures:
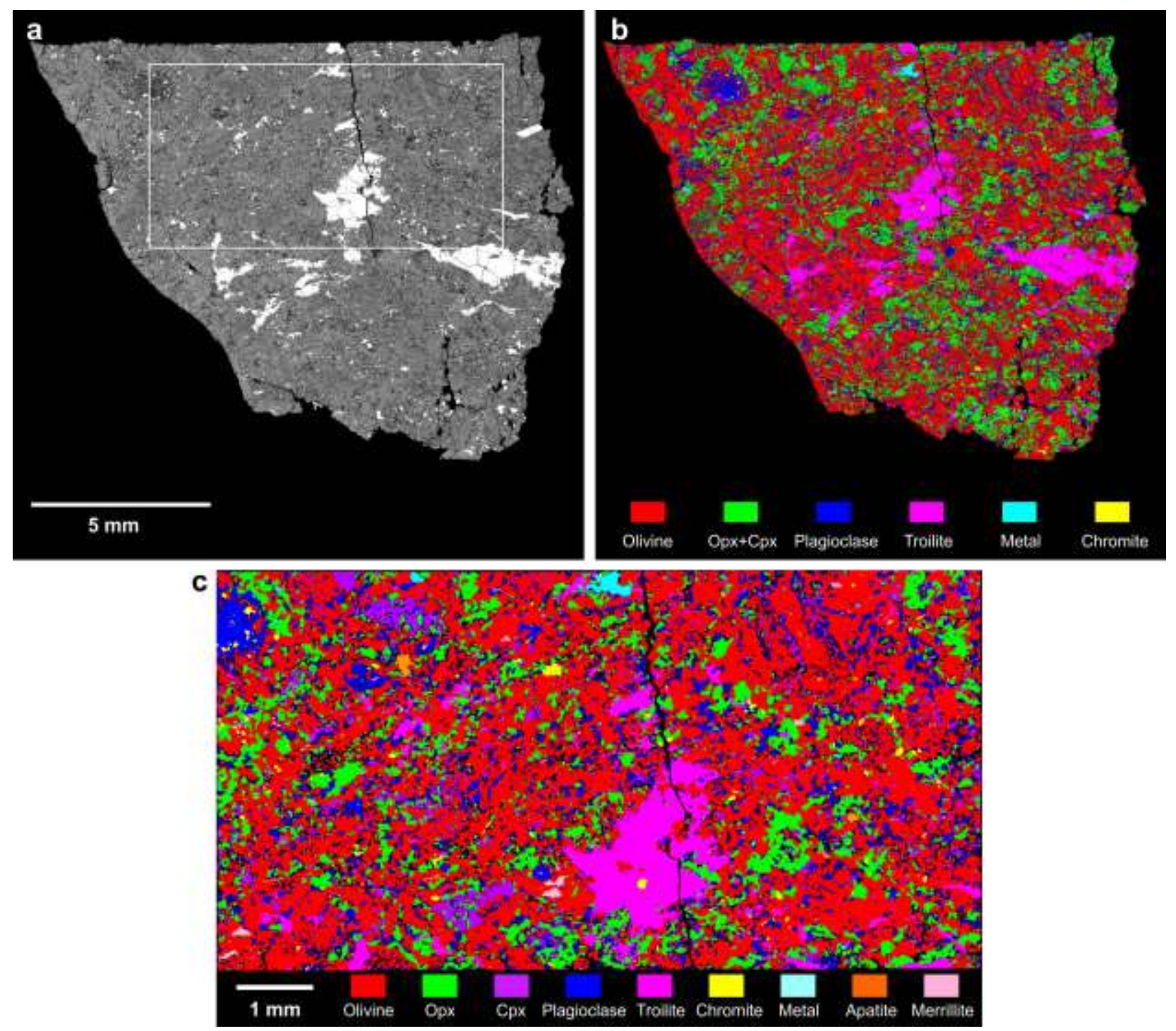

Fig. S1: Modal analysis of the Stubenberg meteorite. a) SEM-BSE mosaic of sample H130,4a. b) Color-segmented phase map of the SEM-BSE mosaic indicating the different mineral phases. Pyroxenes could not be distinguished based on the BSE coefficients. c) SEMEDX phase map of the area marked in a. orthopyroxene (Opx) and clinopyroxene (Cpx) are distinguished based on their Ca contents. 


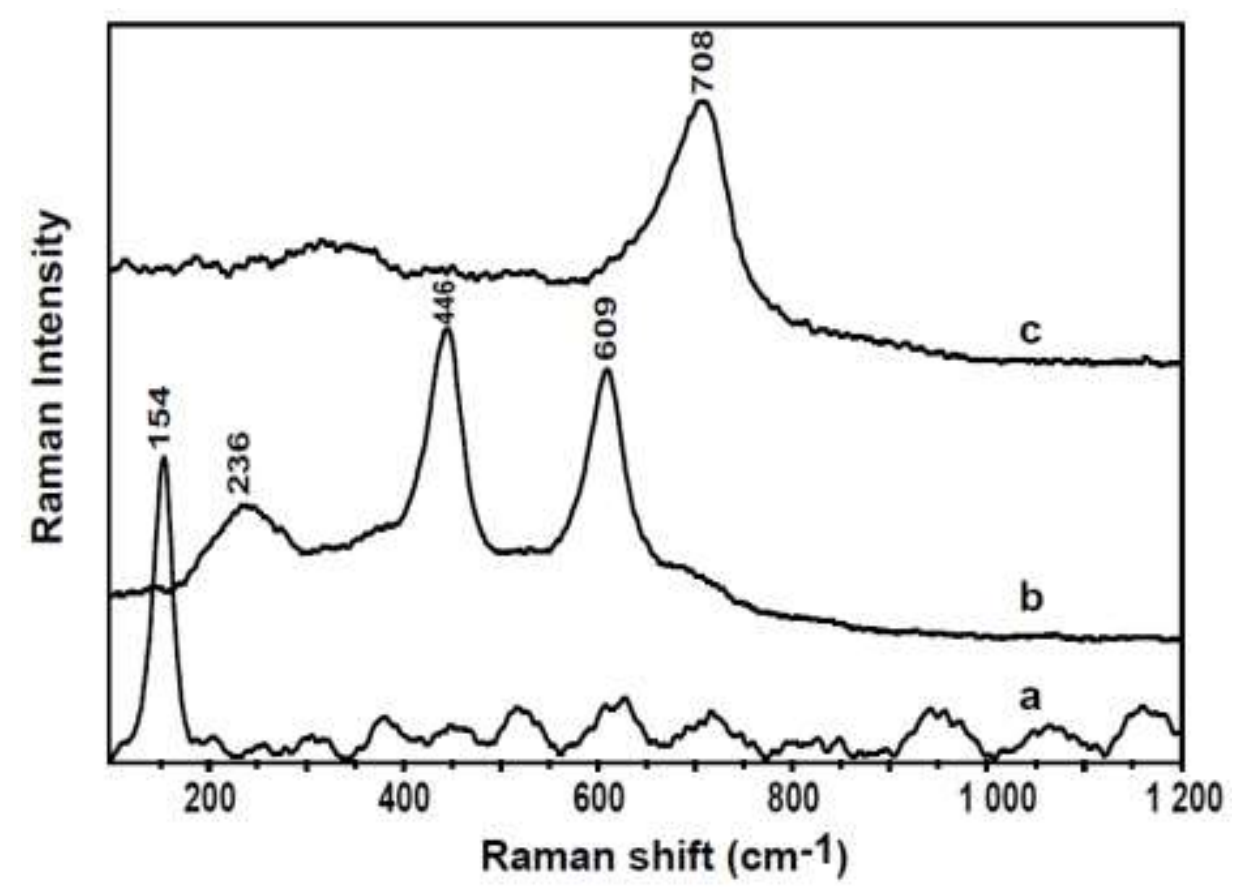

Fig. S2: Raman spectra of anatase (a), rutile (b), and ilmenite (c) from Stubenberg meteorite.

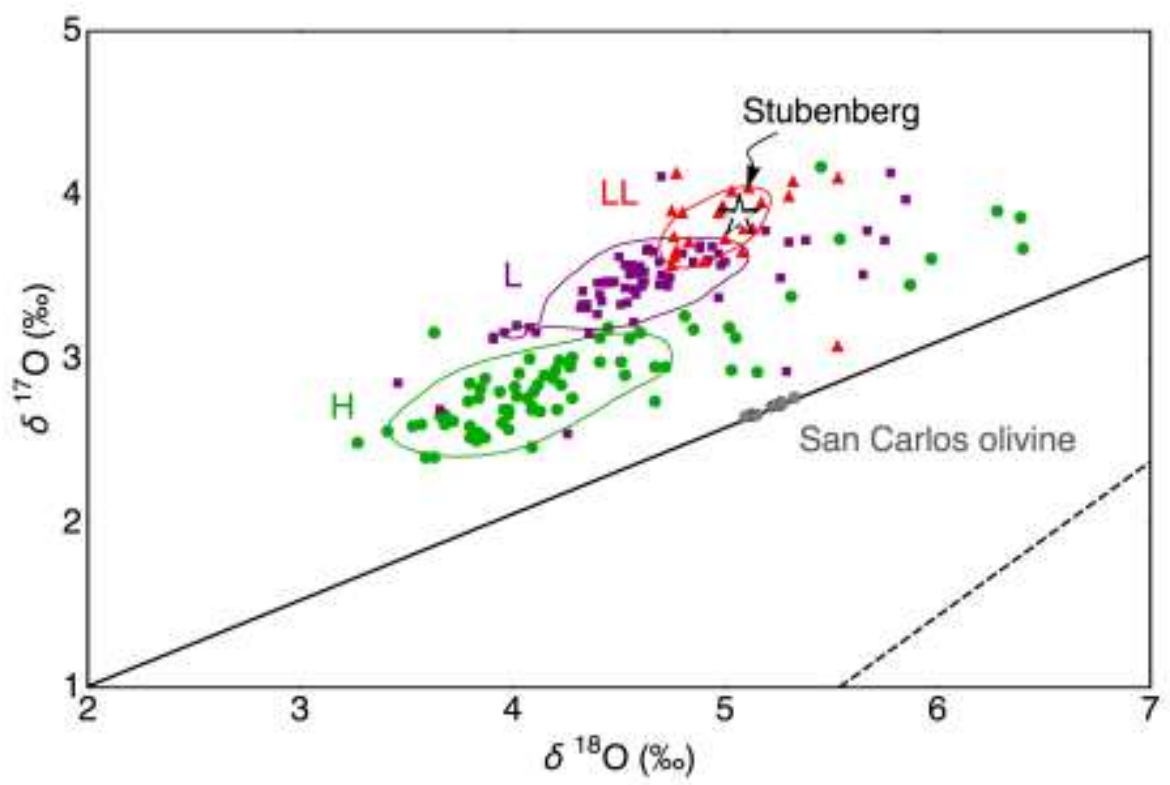

Fig. S3: Plot of $\delta^{17} \mathrm{O}$ vs. $\delta^{18} \mathrm{O}$ of Stubenberg (star) in comparison with published oxygen isotope data of H, L, and LL ordinary chondrites. The results of San Carlos olivine measurements (gray filled circles) are displayed along with the terrestrial fractionation line (solid) and the carbonaceous chondrite anhydrous minerals mixing line (dashed). 


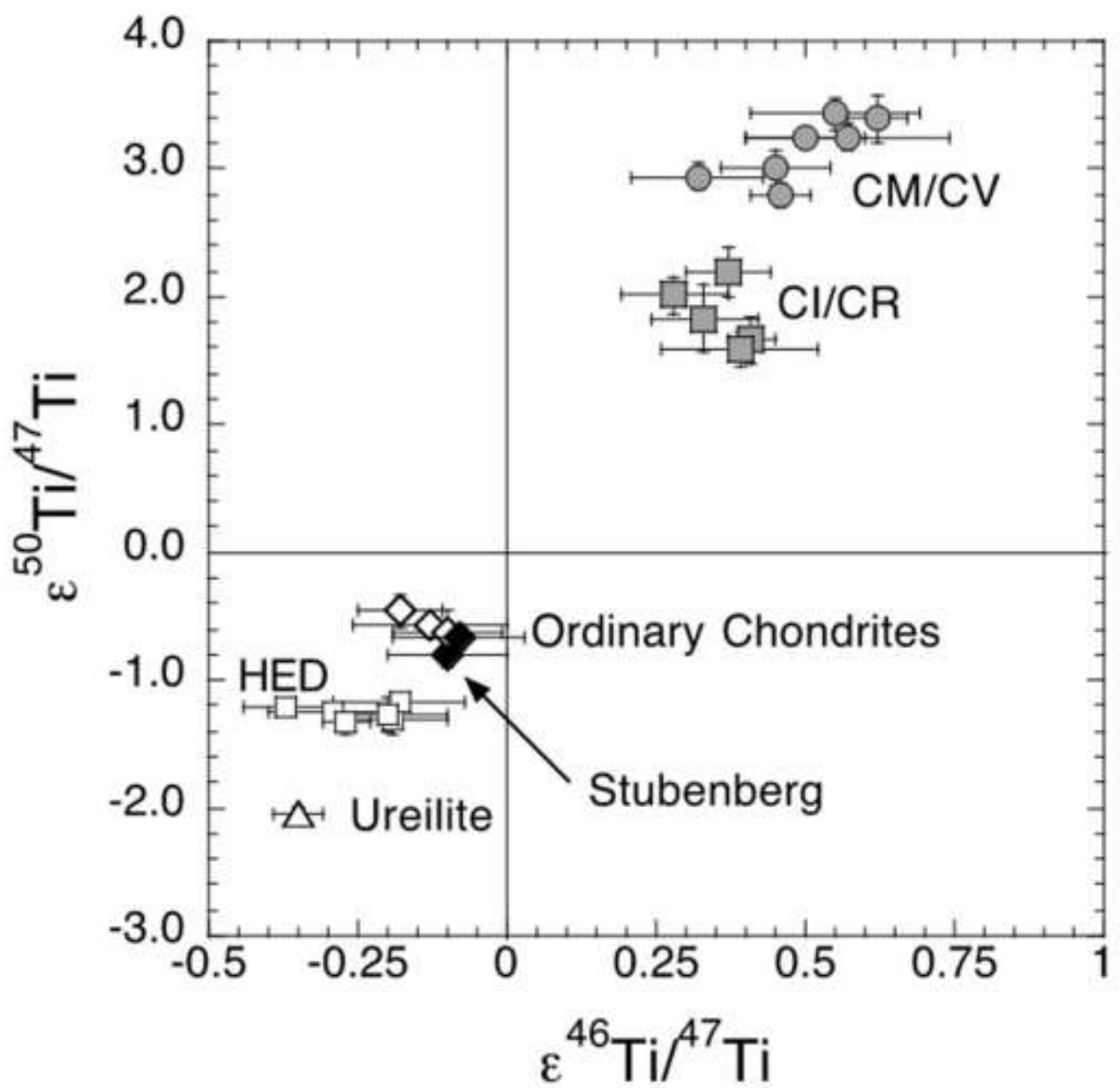

Fig. S4: The Ti isotope compositions $\left(\varepsilon^{46} \mathrm{Ti} /{ }^{47} \mathrm{Ti}\right.$ vs. $\left.\varepsilon^{50} \mathrm{Ti} /{ }^{47} \mathrm{Ti}\right)$ for various meteorite groups. Each group occupies a unique space in the diagram. Black diamonds denote Stubenberg. Data from this study and Williams (2015). 


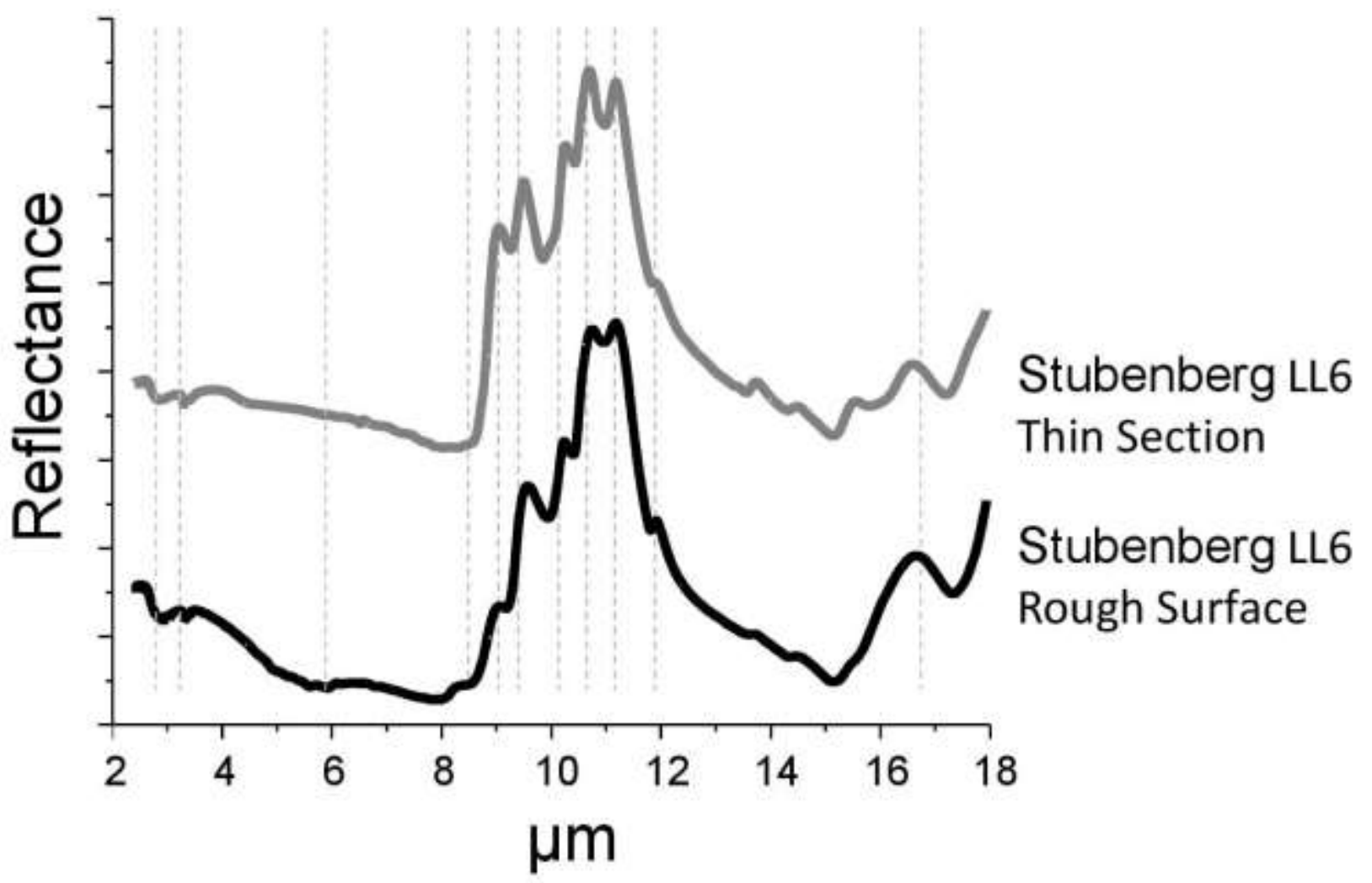

Fig. S5: Mid-infrared spectra of Stubenberg (in wavelength). Vertical lines mark characteristic features discussed in the text. 


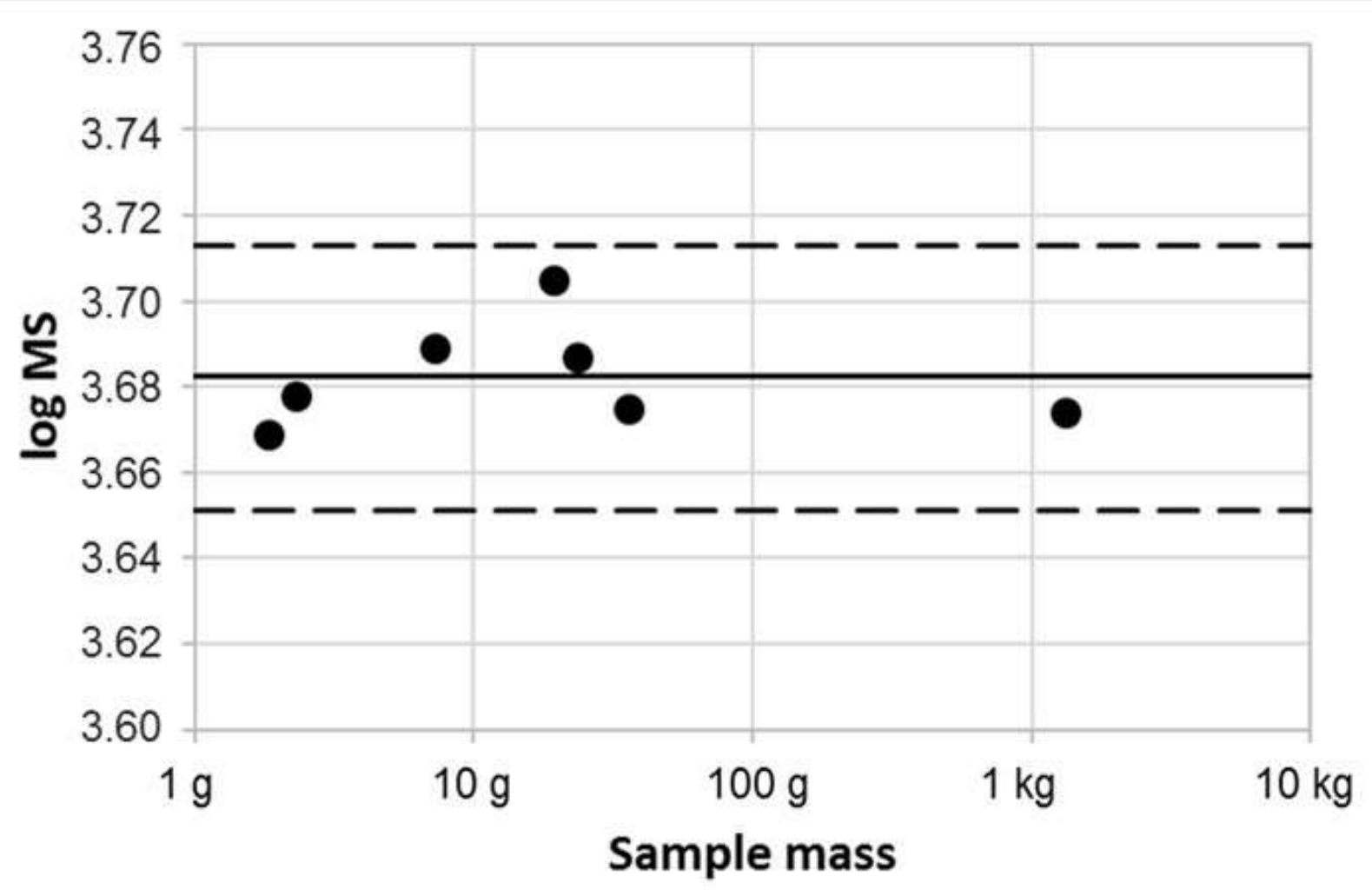

Fig. S6: Magnetic susceptibility values of representative meteorites and fragments of the Stubenberg fall with average (solid line) and confidence interval (dashed lines at $+/-2$ standard deviations of all measured values). 
Table S1: Modal mineral abundances of the Stubenberg breccia (sample M6) obtained from EDS X-ray maps and BSE images. $\mathrm{A}=$ area used for image segmentation.

\begin{tabular}{|c|c|c|c|c|}
\hline $\begin{array}{l}\text { Area \% } \\
\qquad(=\text { vol\%) }\end{array}$ & \multicolumn{2}{|c|}{$\mathrm{A}=50.6 \mathrm{~mm}^{2}$} & \multicolumn{2}{|c|}{$\mathrm{A}=120.5 \mathrm{~mm}^{2}$} \\
\hline Olivine & 50.71 & 55.82 & 45.71 & 53.03 \\
\hline Pyroxene & & & 20.48 & 23.76 \\
\hline Low-Ca pyroxene & 15.14 & 16.67 & & \\
\hline Plagioclase & 9.39 & 10.34 & 11.59 & 13.44 \\
\hline Troilite & 8.48 & 9.34 & 7.44 & 8.63 \\
\hline Diopside & 5.71 & 6.29 & & \\
\hline Chromite & 0.64 & 0.70 & 0.45 & 0.52 \\
\hline Metal & 0.38 & 0.42 & 0.52 & 0.60 \\
\hline Merrillite & 0.23 & 0.25 & & \\
\hline Apatite & 0.16 & 0.18 & & \\
\hline Total & 90.84 & 100.00 & 86.19 & 100.00 \\
\hline
\end{tabular}


Table S2: Chemical composition of metals and troilite within the Stubenberg fragmental breccia. All data in wt $\%$. n.d. = not detected; $\mathrm{n}=$ number of analyses.

\begin{tabular}{l|cccc} 
wt\% & Troilite & Taenite & Kamacite & Pentlandite \\
\hline & $\mathbf{n = 6 7}$ & $\mathbf{n = 3 8}$ & $\mathbf{n = 8}$ & $\mathbf{n = 6}$ \\
$\mathbf{F e}$ & 62.0 & 53.2 & 87.3 & 49.4 \\
$\mathbf{N i}$ & $<0.02$ & 44.3 & 3.9 & 16.3 \\
$\mathbf{C o}$ & n.d & 1.78 & 6.1 & 0.4 \\
$\mathbf{S}$ & 35.9 & $<0.01$ & $<0.01$ & 34.2 \\
$\mathbf{P}$ & $<0.01$ & $<0.01$ & $<0.02$ & n.d. \\
$\mathbf{C r}$ & $<0.02$ & $<0.02$ & $<0.03$ & n.d. \\
$\mathbf{M n}$ & $<0.02$ & $<0.01$ & $<0.01$ & n.d. \\
$\mathbf{C u}$ & $<0.03$ & 0.22 & n.d. & n.d. \\
\hline Total & 97.9 & 99.6 & 97.3 & 99.3
\end{tabular}

Table S3: Concentration of primordial radionuclides (ng g ${ }^{-1}$ for $U$ and Th chains and $\mu \mathrm{g} \mathrm{g}^{-1}$ for $K_{\text {nat }}$ ) in the specimens M1b and M5 of the Stubenberg stone measured by non-destructive gamma-ray spectroscopy. Errors include a 1 Sigma uncertainty of $10 \%$ in the detector efficiency calibration.

\begin{tabular}{lcc}
\hline Nuclide & \multicolumn{2}{c}{ Stubenberg } \\
& M1b (23.58 g) & M5 (1320 g) \\
\hline${ }^{\mathbf{2 3 8}} \mathbf{U}$ & $16 \pm 2$ & $13 \pm 1$ \\
${ }^{\mathbf{2 2 8}} \mathbf{T h}$ & $35 \pm 3$ & $44 \pm 3$ \\
${ }^{{ }^{40} \mathbf{K}}$ & $830 \pm 80$ & $750 \pm 80$ \\
\hline
\end{tabular}

